\title{
African American Males Diagnosed With Schizophrenia: A Phenomenological Study
}

Lorraine Anderson

Virginia Commonwealth University

Follow this and additional works at: https://scholarscompass.vcu.edu/etd

Part of the Nursing Commons

(C) The Author

\section{Downloaded from}

https://scholarscompass.vcu.edu/etd/2563

This Dissertation is brought to you for free and open access by the Graduate School at VCU Scholars Compass. It has been accepted for inclusion in Theses and Dissertations by an authorized administrator of VCU Scholars Compass. For more information, please contact libcompass@vcu.edu. 


\section{AFRICAN AMERICAN MALES DIAGNOSED WITH SCHIZOPHRENIA: A PHENOMENOLOGICAL STUDY}

A dissertation submitted in partial fulfillment of the requirements for the degree of Doctor of Philosophy at Virginia Commonwealth University.

by

\section{LORRAINE B. ANDERSON}

Bachelor of Science in Nursing, University of Connecticut, Storrs, Connecticut, 1968 Master of Science in Clinical Counseling, Our Lady of the Lake University, San Antonio, Texas, 1979

Master of Public Administration, University of Southern California, Los Angeles, California, 1992

Director: DEBRA E. LYON, PHD, RN, FNP-BC, FNAP PROFESSOR AND CHAIR, SCHOOL OF NURSING

Virginia Commonwealth University

Richmond, Virginia

August 2011 


\section{Acknowledgements}

A scholarly dissertation is analogous to a special tapestry in that it reflects the orderly creative alignment of materials and ideas. I wish to thank members of my dissertation committee, Dr. Debra Lyon, Dr. Inez Tuck, Dr. Janet Colaizzi, Dr. Jeanne Salyer and Dr. Shaw Utsey for their facilitation of this weave. I was fortunate to have had the expertise and support of two committee chairs helping me appreciate the warp and the woof underlying the dissertation tapestry I sought to create.

Dr. Debra Lyon, my current chair, kept me focused on the importance of process in ensuring the production of a high quality scientific study. Her guidance and encouragement were invaluable in keeping me on task weaving together philosophic concepts and psychiatric principles as the bases of my study's findings and discussion.

Dr. Inez Tuck, my former chair, consistently emphasized the importance of scholarship as an integral element of the study that I was committed to producing throughout this inquiry. Her expertise in qualitative research and her full range of knowledge of mental health have been a source of inspiration to me. More importantly, she has served as my mentor and advisor since the beginning of my doctoral studies.

If Drs Lyon and Tuck provided me with the fundamental underpinning of the warp and woof (or weft) of the dissertation tapestry, I sought to design; the other members of my committee added a special contribution to facilitate the creation of the image on the final pattern revealed in my dissertation. 
Dr. Janet Colaizzi made a much appreciated transition from a valued clinical colleague in an earlier phase of my career to my invaluable guide into the world of phenomenological inquiry.

Dr. Salyer combined her expertise in chronic illnesses with her considerable skill in structure and formatting to consistently show me a pragmatic approach to research from a practice perspective.

Dr. Utsey kept me always cognizant of the African American cultural impact of my research. Moreover, his diligent oversight prevented me from being enmeshed in misdiagnosis and overdiagnosis concerns as thematic motifs in my research study.

I am exceeding grateful to my family, especially my mother, Mary (May) Alice Ballard who showered me with the love that empowered me to sit down at the loom of learning initially and to continue my weaving until the task was complete.

Finally, John, my beloved husband, has provided a pattern of diligence and a design for excellence during my creative process that cannot be measured, but for which I am profoundly indebted. 
Table of Contents

Page

Acknowledgments

ii

List of Tables

viii

List of Appendices

ix

Abstract

$\mathrm{X}$

Chapter

1 Introduction

History of Mental Illness

History of Schizophrenia

Cultural Variations in Schizophrenia Diagnosis

2 Literature Review

Introduction

Racism as Related to Health Disparities

Impact of Subgroup culture on perception of diagnosis of schizophrenia

Stigma of Schizophrenia

African American Males' Perception of Health 
Role of Family

Recommend Treatment for Schizophrenia

Experience of Schizophrenia

Conclusion

3 Methods

Introduction

Phenomenology

Design, Sample

Procedures

Data Generation

Data Analysis

Data Management

Trustworthiness of the Data 46

4 Findings: The Schizophrenia Experience 49

$\begin{array}{ll}\text { Introduction } & 49\end{array}$

$\begin{array}{ll}\text { Thematic Analysis } & 49\end{array}$

Demographic Data

Content of the Interviews

$\begin{array}{ll}\text { Participant \#1 - Antony } & 52\end{array}$

Participant \#2 - Darius $\quad 53$

Participant \#3 - Tyrone $\quad 54$ 
$\begin{array}{lr}\text { Participant \#4 - David } & \text { vi } \\ \end{array}$

$\begin{array}{ll}\text { Participant \#5 - Paul } & 58\end{array}$

$\begin{array}{lr}\text { Themes } & 58\end{array}$

Theme 1: They know that they are mentally ill 64

Dragged Along by Time 65

$\begin{array}{ll}\text { Symptoms do remain } & 67\end{array}$

$\begin{array}{ll}\text { Summary } & 67\end{array}$

Theme 2: They make a special effort to test Reality 68

$\begin{array}{ll}\text { Summary } & 69\end{array}$

Theme 3: They assert their autonomy 69

$\begin{array}{ll}\text { Accept Me as I Am } & 70\end{array}$

What You See is What You Get 71

Close Community (CC) versus Outside Community (OC) 71

$\begin{array}{ll}\text { Summary } & 73\end{array}$

$\begin{array}{ll}\text { Theme 4: They experience reality differently } & 73\end{array}$

[in which they see themselves as unique]

$\begin{array}{ll}\text { Resilience } & 75\end{array}$

$\begin{array}{ll}\text { Summary } & 76\end{array}$

$5 \quad$ Conclusions, Discussion, Implications and Limitations 77

$\begin{array}{ll}\text { Introduction } & 77\end{array}$ 
Implications for Future Practice, Research and Policy

References 


\section{List of Tables}

Page

1. Table 1 Demographic Information

2. Table 2 Definitions of Overarching Themes

3. Table 3 Example of the Revealing of One Essential Theme (theme 1) from Narratives

4. Table 4 Example of the Revealing of One Essential Theme (theme 2) from Narratives

5. Table 5 Example of the Revealing of One Essential Theme (theme 3) from Narratives

6. Table 6 Example of the Revealing of One Essential Theme (theme 4) from Narratives 
List of Appendices

Page

A. Initial IRB Approval Letter (3/16/11)

101

B. IRB Amendment Approval Letter (7/28/11) 110 


\begin{abstract}
Little is known about how African American men with schizophrenia experience their every day existence. Through applying interpretive phenomenology and using a methodological structure designed by van Manen $(1990,1997)$, this research aimed to enrich the understanding of living with schizophrenia for these African American males. In this study, five men ranging in age from 21 to 57 described their lives within the context of existing with the diagnosis of schizophrenia. The lived experiences across the interviews revealed four overarching themes: They know that they are mentally ill; they make a special effort to test reality; they assert their autonomy and; they experience reality differently, which they see as a gift. To provide appropriate treatment support to African American male diagnosed with schizophrenia, it is important to recognize the client's ability to assert his autonomy and appreciate his view of himself as unique and special. Moreover, in terms of symptom management, it is pivotal to understand that although the client may not be free of hallucinations and delusions, he nevertheless may be at his optimum state of wellness. The realization that these men have been transformed by their diagnosis of schizophrenia rather than being crushed by their condition is evident in their stories.
\end{abstract}

Keywords: African American, schizophrenia, males, phenomenology. 


\section{Chapter 1}

\section{Introduction}

In the United States, approximately $6 \%$ percent of Americans, ages 18 and older in a given year suffer from a diagnosable serious mental illness. When applied to the projected 2010 United States Census residential population for ages 18 and older of 235, 016,000 people, this represents over 14 million people diagnosed with serious mental illness (U.S. Census Bureau, 2010). Annually, 1\% of the United States' population, or 2.4 million persons, are diagnosed with schizophrenia (Kessler, Chu, Demier, \& Walters, 2005).

Schizophrenia is a chronic, severe, and disabling brain disorder (Regier et al. 1993). In classifying symptoms of schizophrenia, clinicians use three broad categories:

positive, negative, and cognitive symptoms, (First, Frances \& Pincus, 2002; Varcarolis \& Halter, 2010). First of all, positive symptoms include hallucinations (sensory experiences undetected by other), which may be auditory (the most common), visual, olfactory, gustatory or tactile. The presence of delusions, "false beliefs" is another positive symptom. These "false beliefs" frequently are of a persecutory or grandiose nature. Disorganized thinking that may result in associated looseness of speech is an additional positive sign of the condition. Movement disorders including posturing, agitation, or catatonia represent still another type of positive symptom of schizophrenia. 
Secondly, negative symptoms include the following: flat affect, ahedonia (lack of pleasure in everyday life), amotivational syndrome, or apathy (lack of ability to begin and sustain planned activities), and poverty of speech (engaging minimally in conversation, even when forced to interact). A third set of symptoms profoundly impacts the individual's cognitive abilities. These findings include: diminished ability both to understand information ( processing) and use it to make decisions, difficulty focusing attention and concentration, and problems with the ability to use information immediately after learning it (executive functions). In addition, concrete thinking and impaired abstraction are noted in individuals diagnosed with schizophrenia.

\section{History of Mental Illness}

Behaviors that suggest mental illness characterized by irrational or uncontrolled behavior were reported even in ancient writings including the Bible (Heinrichs, 2003). Terms such as madness, deviance, lunacy, and insanity reflect the existing values and beliefs of the society and culture of the time period. Therefore, it can be said that a culture's concept of mental illness is one that is socially constructed and interpreted based on language, beliefs and a particular historical context (Walker, 2006). As background for this study, my focus in the literature has been on historic trends regarding mental illness in the United States.

In colonial times, many believed that the mentally ill were possessed by the devil, and therefore, prayers, threats, and physical punishment were employed as the treatments of choice for these supposed victims of Satan. During the same era, and in other locations, there were some attempts to provide organized services to mentally ill 
individuals, but for the most part, people were kept at home, or placed in jail, if they became violent.

In Williamsburg, Virginia, the first public psychiatric institution in the United States was opened in 1773 . The drive for the asylum came as the result of an insane homicide reported in the Virginia Gazette in 1769 (Colaizzi, 2004). The facility was built to confine the mentally ill; not to provide a treatment environment. The name of the institution evolved from the Public Hospital for Persons of Insane and Disordered Minds (1773), to Eastern Lunatic Asylum (1841) to its present name, Eastern State Hospital (1894) (Colaizzi, 2004). These name modifications reflect the progressive change in philosophy concerning the proper appellation of an institution dedicated to the treatment or confinement of mentally ill persons. In the antebellum period, African Americans, both slave and free, were admitted to Eastern State provided there was no white person, who required the bed.

After the Civil War in 1868, Central State Hospital in Petersburg, Virginia was established as a state psychiatric facility for African American patients. In 1968, Eastern State Hospital was integrated, having been previously for white patients only. According to Colaizzi (2004), the two previously segregated facilities exchanged patients to achieve integration, a process that occurred apparently without incident or notice by the respective communities. Eastern State Hospital and Central State Hospital are examples of how some public psychiatric facilities, historically, were separated by race in accordance with local customs and state laws. 
Dorothea Dix (1802-1887), a New England school teacher, succeeded in drawing national attention to the treatment of the mentally ill. In 1841, after seeing the deplorable conditions at the local jail in East Cambridge, Massachusetts, where the mentally ill were incarcerated, she began a crusade for improvement in the care of the insane throughout the country (Thompson, 1994). Dix provided detailed reports of her visits and investigations into jails and almshouses. Her work resulted in the construction of 32 institutions in several states for the purpose of providing humane care for the indigent, mentally ill persons. These asylums, as they came to be called, for the most part, initially provided an improvement in care as compared to previous conditions (Coleman, 1992). However, as the census in these institutions grew (some had over 3000 patients), the care provided became primarily custodial (Geller 1994). The asylum era reflected the belief that custodial care was required to provide for protection of the mentally ill, as well as, guarding society from these individuals. This approach was seen as more humane than the handcuffs and leg irons that previously had been employed for this purpose.

The next phase of care, the mental hygiene period, dating from the early to the mid $20^{\text {th }}$ century, was primarily based on the view that mental disorders were caused by poor environment in childhood and inherited deficiencies. These beliefs led to practices such as draconian marriage laws, biased immigration regulations, and involuntary sterilizations. For example, it was reported that a total of 18,552 mentally ill persons (approximately 8,000 in Virginia), were sterilized, involuntarily during the first half of the $20^{\text {th }}$ century (Thompson, 1994). Laws were passed to make it permissible for state mental facilities to perform these sterilizations (Gamble, 1945). The eugenics movement 
resulted in the first genetics-based sterilization law being enacted in Indiana in 1907 , followed closely by Connecticut. In 1924, Virginia passed two eugenic-related laws. The first, the Racial Integrity Act, defined a white person as having no trace of black blood and made it illegal for whites and non-Caucasians to marry. The second permitted involuntary sterilization. Under this latter act, those labeled "feebleminded" including the “insane, idiotic, imbecile, or epileptic” could be sterilized. In a 1927 landmark decision, the United States Supreme Court upheld Virginia's involuntary sterilization of Carrie Buck, a white female, in an 8-1 ruling written by Justice Oliver Wendell Holmes. Recently in a House Joint Resolution, the House of Delegates, the Senate concurring, expressed regret over the Commonwealth's role in the eugenics movement (Virginia House of Delegates, 2001).

With the advent of psychotropic medications, de-institutionalization became a trend, associated with the concomitant view that all psychiatric hospitalizations were adverse and unnecessary. This change was accompanied by a belief that all mental health patients could be treated as outpatients in the community with minimal need for inpatient stays. The Federal Community Mental Health Act (CMHA) was passed in 1963 as part of President John F. Kennedy's New Frontier. Although the purpose of the CMHA was to support community based care as an alternative to institutionalization, in some jurisdictions the law was used as an excuse to close expensive inpatient facilities without spending funds for community based care. Accordingly, community mental health programs grew with little evaluation of their efficacy, or program outcomes. Currently, in the managed care environment, emphasis is placed on the cost effectiveness of providing 
for mentally ill persons within societal demands for humane and restorative options. In 1996, the Federal Mental Health Parity Act (MHPA) was signed into law. This law requires that insurers provide the same dollar amounts to their insured for the care of mental illness as they allow for care of somatic illnesses.

\section{History of schizophrenia}

Schizophrenia has an equally socially charged history, interwoven with that of mental health in general along with some unique contextual implications. The word 'schizophrenia comes from the Greek and roughly translates as 'split mind'. Paul Eugen Bleuler (1857-1939), a Swiss psychiatrist, created this term in 1908 to denote a group of mental disorders that German psychiatrist Emil Kraepelin (1856-1926) had called “dementia praecox”, Latin for 'premature dementia'(Fraguas \& Breathnach, 2009, p.62) . Kraepelin subscribed to the idea that the major causes of psychiatric diseases were biological and genetic abnormalities and that the clinical findings usually occurred at a youthful age, e.g. adolescence. He noted a new set of diagnostic findings based on the classifications of a common pattern of symptoms. In addition to classifying schizophrenia, Kraepelin described manic-depressive disease, which now is believed to represent a range of mood disorders including major depression and bipolar disorder. Although he was a contemporary of Sigmund Freud (1856- 1939), Kraepelin's work did not obtain the same public acknowledgement, but nevertheless, his theories were well known and were influential in the scientific arena. Kraepelin's theories on the etiology and diagnosis of schizophrenia formed the basis of major diagnostic systems now in use, especially The American Psychiatric Association's Diagnostic Statistical Manual (DSM 
IV- TR) and the World Health Organization's International Classification of Diseases (ICD) system (Berrios, Luque, \& Villagran, 2003 ; Fraguas \& Breathnach, 2009).

Sigmund Freud, the Austrian neurologist, developed theories of personality structure and stages of psychosocial development that influenced psychodynamic models used in the treatment of mental illnesses in general, and schizophrenia in particular. His thinking and writings about mental health disorders remain influential in clinical therapeutic approaches, particularly in what is known as 'talk therapy' (Varcarolis \& Halter, 2010). Even psychotherapists who reject Freud's theories, follow his psychoanalytic approach.

Bleuler, also a contemporary of Freud, was initially a supporter of psychoanalytic theory, but later changed his stance on the etiology of schizophrenia to be more in line with that of Kraepelin. Bleuler renamed Kraepelin's dementia praecox, schizophrenia, because he did not believe that the disorder resulted in mental decline as indicated by the term 'dementia', nor that it was restricted to youth as indicated by the word 'praecox' (Fraguas \& Breathnach, 2009, p.62)

Heinrichs (2003) states that the current diagnostic criteria for schizophrenia can be traced to the turn of the twentieth century. However, he is cautious to distinguish this diagnosis from other mental disorders of the time. He asserts that what distinguishes schizophrenia from other mental conditions reported throughout history is the noted persistent psychosis in young people that is not a product of other medical or druginduced conditions. 
In the United States, the history of the treatment of schizophrenia did not differ significantly from that of other serious mental disorders until the 1960s. Several changes occurred during this time period in this country. First, the introduction of antipsychotic medications had a major impact on the treatment of this condition. This pharmacological innovation greatly decreased the frequency and duration of inpatient hospitalizations for this cohort of patients by allowing individuals with the diagnosis to live outside of institutional settings.

Secondly, there emerges a basic principle of health care that diagnosis drives treatment. Moreover, diagnosis also reflects different theoretical views of the mental illness. A significant approach in mental health diagnosis has been the effort to establish universal criteria for a diagnostic category. The Diagnostic and Statistical Manual of Mental Disorders IV-TR (DSM IV-TR) is considered a technical manual for practitioners and its use affects how millions of dollars are allocated for mental health research, diagnosis, and treatment (Kirk \& Kutchins, 1992). The manual was written with input from a variety of clinical specialties to standardize the process of diagnosis. The manual has been revised several times, receiving input from psychiatrists in research and practice. With respect to DSM I through DSM IV-TR, patient diagnosis depends on which manual was used by the clinician. Most clinicians use the manual in daily practice. Kirk and Kutchins (1992) are among a minority that traced the evolution of the DMS I to the current DMS IV-TR and make a compelling argument that serious validity and reliability problems exist with this classification system. They argue there is evidence that psychiatrists in several documented cases were unable to agree on which persons 
were mentally ill, as well as, what type of illness they had. In addition, these same clinicians could not concur consistently on placement of people into official diagnostic categories with more than a 50\% agreement (p.39). Kirk and Kutchins believe that this lack of reliability has led to clinician bias in making diagnoses. Such a position raises the possibility that similar validity and reliability issues also may be contributing factors in the misdiagnosis of African American males with schizophrenia.

Finally, using schizophrenia as an example, Metzl (2009) makes a case for the relationship between race and the diagnosis of insanity in the United States. Before the onset of the civil rights movement, the author states that medical and public opinion indicated that people diagnosed with schizophrenia most often were white, thought to be harmless and typically, were middle-class females. The behaviors of these individuals were considered embarrassing and worrisome at worse. Metzl notes that this view changed over time. He further states that the perceived schizophrenic symptoms of African American patients were conflated with the so called "schizophrenia" of civil rights protests, a particular label associated with black organizations such as the Black Panther Party and the Nation of Islam. As previously reported by several authors cited in this paper by Metzl, it is believed that many physicians in the United States have over diagnosed schizophrenia in African American males (Barnes, 2008; Williams \& Williams-Morris, 2000).

\section{Cultural variation in schizophrenia diagnosis}

Although worldwide, schizophrenia has been found in all racial and ethnic groups, the United States has had some peculiar nuances of diagnosis by race. The 2010 
U.S. census lists approximately 42, 163,000 persons as Black of African American descent of which 19,057,000 are male (U.S. census, 2010). African American males make up $45 \%$ of the African American population, and yet when compared to all women, white men and all other ethnic groups in the United States, African American men are diagnosed with schizophrenia to a disproportionate degree in inpatient settings (Barnes, 2008; Metzl, 2009; Snowden \& Cheung, 1990). Schizophrenia is found more commonly in males than females at a ratio of 1.4:1 (Varcarolis \& Halter, 2010, p.307). However, even although the distribution of the disease is observed to be only slightly more likely for males in the general population, as noted above, the African American male is much more likely to be diagnosed with schizophrenia when presenting for treatment (Barnes, 2008; NIMH, 2008). This subpopulation, also, is reported by clinicians to be more aggressive, paranoid, and violent than females and members of other ethnic groups (Esterberg, Compton, McGee, Shim, \& Hochman, 2008; Whaley, 2004a). As a result of these perceptions, this particular subset of mental health patients is likely to be treated differently from others with schizophrenia. Research indicates that the attribution of violence or aggression to Blacks seeking mental health services often represents a form of bias associated with racial stereotyping, especially related to black males (Whaley, 2004b).

According to Williams and Williams-Morris (2000), over-diagnosis of paranoid schizophrenia and the under-diagnosis of affective disorders could be due to an acceptance of negative stereotypes of Blacks which may be a contributing feature to misdiagnosis. Another possible explanation is that African Americans with mood 
disorders may be less likely to seek mental health treatment (USDHHS, 2001). Clinicians implementing a similar set of criteria coming to divergent conclusions because of their use of different diagnostic instruments are another potential reason for misdiagnosis. An additional possible explanation is that clinicians unfamiliar with the cultural norms of African American behavior bring their own unexamined biases into the assessment process (Trierweiler, et al., 2005).

The concept of "unmet need" was based on the U.S. Surgeon General's report on culture, race, and ethnicity (Department of Health and Human Services, 2001), which identified access to care as a major issue involved in mental health disparities involving the African American population. According to Mishra et al. (2009), “despite similarity in the incidence of mental illness across racial and ethnic groups, minorities have a greater burden of unmet mental health needs, due in varying degrees to patient, provider, and health system barriers" (U. S. Department of Health and Human Services, 2001,p. 117). African American males diagnosed with schizophrenia, in particular, have experienced a host of unmet mental health needs (Fiscella et al., 2002). In Mishra's view, the key reasons that this particular group of mental health patients fail to have their treatment needs met are barriers affecting access to care, including stigma, concerns of confidentiality, and mistrust (2009, p.122). Stigma may lead individuals to hide or deny their distress in order to avoid ridicule. A number of authors have concluded that racism is an aspect of stigma (Anglin, 2006; Corrigan, 2007; Hines-Martin, 2002; Hines-Martin et al., 2003). Other unmet needs have been noted to arise due to inadequate detection and 
recognition of mental health symptoms in African Americans, often leading to improper diagnosis (Borowsky et al., 2000).

Corrigan et al. (2010) reported that diagnostic labeling has a significant negative impact on individuals. This labeling contributes to the idea that people with certain diagnosed mental illnesses, particularly schizophrenia, never recover. He emphasized that labeling stigmatizes these individuals, thus diminishing their opportunities in areas such as obtaining work, getting decent housing, and maintaining desirable social relationships. Corrigan further suggested that often people choose not to seek mental health services in order avoid the label of "mental patient." Once so identified, the authors asserted, these persons suffer discrimination and prejudice as a result of the diagnostic label.

The over-diagnosis and misdiagnosis of schizophrenia, racism, stigma, unmet treatment needs, and lack of access to mental health care affect African American males disproportionately. Furthermore, these issues may contribute to how African American men view themselves and their illness. According to Corrigan et al. (2010), people who agree with and apply self-stigmatizing labels may suffer consequences including diminished self-esteem and decreased self-efficacy. This incorporating of negative stereotypes can contribute further to this population's unmet health care needs by increasing their reluctance to seek care.

As indicated earlier, African Americans males with mental illness have unmet needs. This finding is further supported by research on health disparities (Newhill \& Harris, 2007; DHHS, 2001). A primary aim of this study will be to understand the experiences of African American males diagnosed with schizophrenia. A secondary aim 
will be to help bridge any gap in knowledge that informs service, by interviewing this group of individuals so as to better determine their inherent needs and address their specific condition. One way of determining potential treatment strategies that could address these needs is by listening to the stories (lived experiences) of individuals living with the diagnosis of schizophrenia. The researcher will seek to discern from their stories, approaches that lead to a better understanding of the illness experience, including how these study participants cope with their condition. Another possible outcome is the discovery of previous undisclosed strengths within those individuals that have not been identified in the mental health literature that might impact clinical practice.

Moreover, through studying the experiences of African American males diagnosed with schizophrenia, a coterie of those with serious mental disorders that is an understudied population, the investigator plans to add to scientific knowledge in the field of mental health nursing. She is convinced that, better understanding among nurses of the meaning of schizophrenia to African American males can have a positive impact on the health care that nurses provide such patients in a variety of clinical settings.

As noted earlier in this chapter, there remains considerable uncertainty with regard to the issue of misdiagnosis and over-diagnosis of schizophrenia in the African American male population. Are these two concerns theoretically based, or empirically demonstrated? It is well accepted that obtaining a good history from the patient is essential to accurately diagnosing a somatic illness, e.g. diabetes mellitus. The researcher postulates that similarly, information discovered from examining the lived experiences of African American males diagnosed with schizophrenia can help resolve uncertainty about 
this condition and lead to more accurate diagnoses. The literature is replete with studies that demonstrate opportunities for improving assessments and enhancing therapeutic outcomes.

The implications for mental health care and nursing practice are significant. A key outcome of the study will be that nurses can implement a more culturally sensitive approach during the initial diagnosis of schizophrenia. These professionals can help defer the diagnosis of schizophrenia while collecting data, or consider reevaluating the diagnosis after the symptoms have abated (Hampton, 2007). Secondly, nurses can include the understandings gained from the study to help with accurate diagnosis in the inpatient setting and work with the families of African American males to coordinate appropriate outpatient services. It is further anticipated that outcomes from this study will enhance the ability of advanced practice nurses to more accurately assess and treat mental health patients in their care. 


\section{Chapter 2}

\section{Literature Review}

\section{Introduction}

This chapter contains a review of the literature that informs the study of lived experiences of African American males diagnosed with schizophrenia. The subjects examined in greater depth than in Chapter 1 are: Racism as related to diagnosis, Impact of culture on perception of diagnosis of schizophrenia, Stigma of Schizophrenia, African American males' view of health, Role of family, Recommended treatment for schizophrenia, and Phenomenological Studies and Schizophrenia. While more studies have been done, there is a paucity of research on this topic as related to race.

\section{Racism as related to health disparities}

Another contemporaneous emphasis in the mental health literature has centered on application of the diagnosis of schizophrenia within the context of racism and health disparities in the United States (Neighbors et al., 2003; Suite et al., 2007). The authors indicated that the over-diagnosis of paranoid schizophrenia and the under-diagnosis of affective disorders are frequent occurrences in the black community. Some evidence suggests that these misdiagnoses may be due to conscious or unconscious negative stereotyping based on misconceptions and inaccuracies concerning the psychology of African Americans, yielding disparate treatment implications (Williams \& WilliamsMorris, 2000; Williams, 2007). 
Snowden (2003) noted that racial and ethnic disparities are as widespread in the diagnosis and treatment of mental illness as they are in other areas of health. He documented the disparities in access and quality as described in epidemiological research that consistently reveals that African American and other non-white groups in the population needing outpatient care are unlikely to receive it. Research has demonstrated, moreover, that African Americans are greatly over represented in mental health inpatient settings and in psychiatric emergency rooms. From a quality perspective, other researchers have observed that African Americans and other members of the minority groups are less likely than Whites to receive guide-adherent treatment when suffering from anxiety disorders and depression. Other findings include the fact that African Americans received a greater number of injectable antipsychotic medications when compared with Caucasians.

Snowden (2003) examined explanations other than bias to explain the mental health disparities for African Americans with respect to access, continuity and quality, including socioeconomic differences, insurance coverage, and lack of familiarity with mental illness. He concluded that although direct evidence was limited, it nevertheless was reasonable to believe that bias, at least partially, explained these disparities.

In a study designed to investigate the relationship between race and psychiatric hospital diagnosis at state facilities in Indiana, Barnes found that major depressive disorder and bipolar disorder were under diagnosed and schizophrenia was over diagnosed in African American clients who were involuntarily admitted. According to the author, of the 2, 404 admissions reviewed, 82.7\% of the African Americans, compared 
with, $49.3 \%$ of the Caucasian clients were diagnosed with schizophrenia. In comparison with all other diagnostic subgroups, African American patients were more likely to be diagnosed as schizophrenia, paranoid subtype, or schizophrenia, undifferentiated subtype offering support for bias interpretation..

Supporting the perception of inaccurate and inappropriate diagnosis of African Americans with mental disorders, Greenwald and Banaji (1995) discussed the history and automatic operation of stereotypes, particularly in the area of racial prejudice, even in the absence of awareness of those influences on the part of the individual. The authors described a concept that they referred to as aversive racism, which they defined as a conflict "between feelings and beliefs associated with a sincerely egalitarian value system and unacknowledged negative feelings and beliefs about Blacks" (p. 15).

The explanations proposed by Greenwald and Banaji (1995) indicate that bias may be introduced into the process of diagnosis related to a clinician's lack of cultural competence or imprecision inherent in the use of unstructured interviews, combined with clinician bias. Studies suggest that when using flexible diagnostic interviews, clinicians apply different decision rules to African American patients when assessing them for schizophrenia (Neighbors et al., 2003). In an article published in 2000, the authors examined the different decision rules applied to African Americans and non-African Americans evaluated for mental health problems. It was noted that hallucinations and paranoid /suspicious attitude more often were attributed to African American patients; elevated mood and the combination of negative symptoms and dysphonic mood more often were attributed to non-African American patients. Attributions of negative 
symptoms seem to have been particularly linked to the diagnosis of schizophrenia in African Americans. The authors' research findings suggested that diagnostic differences may result from clinicians attributing and weighing particular observations differently for patients of different races (Trierweiler et al. 2000).

Trierweiler, Muroff, Jackson, Neighbors, and Munday (2005) explored the relationship between situation attributions in clinicians' statements justifying psychiatric diagnosis and the specific judgment rendered. Findings included the observation that African American clinicians used information more frequently and linked that that information differently to their diagnostic decisions. One of the possible explanations for this disparity in assessment methodology was that African American clinicians attend more consistently to situation information in all their communications with patients, which may in turn reflect more intimate understanding of their own community and the potential impact of social conditions on the mental health of its members. African American clinicians seem to have considered contextual factors regardless of the severity of the condition. The authors theorized that situational information may provide a way of exploring more thoroughly the meaning of apparent symptoms for a particular patient providing a localized validation of the diagnosis. Non-African American clinicians by contrast would not be expected to have an intimate grasp of life in an African American community, nor have doubts about the applicability of the DSM-IV TR concepts within the community. Findings from the lived experiences of study participants might be useful in validating the significance of situational attributions in the diagnosis and treatment of their condition. 
In a multidisciplinary study, Minsky, Vega, Miskimen, Gara and Escobar (2003) examined ethnicity and the diagnosis of psychosis in African Americans, Latinos, and European Americans. These investigators employed three research questions in their study. Are African Americans in their clinical population disproportionately diagnosed as having schizophrenia? The answer was affirmative. Were Latino patients more likely to be disproportionately diagnosed as having schizophrenia? The answer was negative. Finally, the researchers inquired, are clinical assessments using standardized instruments compatible with traditional diagnostic assessments? The investigators reported discordant results. African Americans were more likely to be diagnosed as having schizophrenia, despite vague unremarkable levels of self-reported psychotic symptoms. Latinos were more likely to be diagnosed with having major depression, despite increased levels of psychotic symptoms and depressive symptoms. Possible interviewer bias was suggested when clinicians applied DSM IV criteria to patients. The lived experience study of African American males diagnosed with schizophrenia should be of significant value in helping to address the incongruencies between self-reported symptoms of these patients and the psychotic diagnoses that were rendered.

Two seminars held at Dartmouth College, September, 2008, and Howard University in December 2008, that included psychiatrists, anthropologists, social scientists, psychologists, and graduate students in the health services, examined the mental health services experience of African Americans in different rehabilitation programs in the Washington DC area (Carpenter-Song, Whitley, Lawson, Quimby, \& Drake, 2009). Central concerns identified by the African American community included 
problems with access to and utilization of treatment; inequalities in the quality of care that African Americans receive including physicians delivering less information, less supportive talk, and less proficient clinical performance to African Americans than to Euro Americans. Problems communicating with mental health providers were perceived by African American consumers to constitute a major obstacle to seeking services.

With respect to conditions experienced by those diagnosed with schizophrenia, investigators found that African Americans are more likely than their Euro American counterparts to receive higher dosages of medications, more medication, and depot antipsychotic medications and less likely to receive second-generation psychotropic medications. The authors concluded that these findings were possibly due to bias as well as access problems such as, poverty providing further evidence of disparate care or treatment.

Misdiagnosis can have a severe impact on the outcomes experienced by the patient. For example, clearly such a diagnostic error can affect the therapeutic options offered. The expectation for recovery of the individual diagnosed with schizophrenia may be diminished by the treating clinician and by the patient himself as compared to an individual diagnosed with bipolar disorder or depression (Suite et al., 2007). This inaccurate delineation moreover, can result in self-stigma and blocked life goals (Corrigan, 2007).

\section{Impact of subgroup culture on perception of diagnosis of schizophrenia}

In contrast to the current depiction of 'culture' as a trait list, researchers have determined "that 'culture' is a complex dynamic process through which shared symbols 
and meanings created through social interactions orient how persons think, act, and feel in the world (Carpenter-Song et al., 2009,p.5)." The aspects of 'culture' identified by the researchers include stigma, perception and family. The impact of culture on mental health has been of interest to social scientists for many years. In a study of causal beliefs of lay urban African Americans related to schizophrenia, Compton, Esterberg, and Broussard (2008) found that some $47.9 \%$ of those in the study reported one or more esoteric factors as the cause. Three of the most common causes, from a list of 30 possible etiologies, noted by these members in the black community were; possession by evil spirits, radiation, and punishment by God. These responses were selected even among participants who chose disturbance of brain chemistry and drug/alcohol abuse approximately $40-50 \%$ of the time. The community attitudes and beliefs may influence the treatment seeking behaviors of African American males diagnosed with schizophrenia. The under treatment of these males is part of the unmet needs, previously discussed (Hines-Martin et al., 2003).

\section{Stigma of schizophrenia}

In viewing the experience of schizophrenia, according to Anglin, Link, and Phelan (2006), African Americans were more likely than Caucasians to believe that individuals with schizophrenia are violent; however, they were less likely to think that these persons should be blamed and punished for violent behavior. Although noted as a cultural belief, there is no evidence, in fact, to support the idea that people with schizophrenia are more violent toward others. On the contrary, based on the work of Walsh, Buchanan, and Fahy (2002), the NIMH concluded that the risk of outward 
directed violence among people with schizophrenia is small. However, the risk of attempted suicide is higher than in the general population, as about 10 percent of persons with schizophrenia (particularly young adult men) die by suicide, annually (NIMH, 2008).

In terms of expressed attitudes toward people with schizophrenia in the African American community, a qualitative study conducted by Esterberg, Compton, McGee, Shim, and Hochman (2008) revealed that the majority of the respondents stated they were not comfortable with the idea of dating or living with a person with schizophrenia. The respondents also reported only slight comfort with being in close proximity with individuals diagnosed with schizophrenia in settings, such as work and environments where they were expected to engage in casual conversation. Further, the participants reported minimum comfort with having a friend or neighbor with schizophrenia. These findings were similar to those described in another study that explored attitudes of African Americans toward mental illness that were seeking treatment (Matthews et al., 2006). These reported attitudes included: (1) a high level of embarrassment and refusal to accept their need for mental health services; (2) perception that being labeled mentally ill resulted in limited life opportunities; (3) possession of strong and consistent negative attitudes about medication use and; (4) the observation that mental health consumers described the detrimental impact that the stigma of mental illness had on their lives e.g. shame, embarrassment, and rejection (Matthews, Corrigan, Smith, \& Aranda, 2006). Stigma associated with severe mental illness appears to present a significant barrier to assessing mental health services for African American males. 


\section{African American males' perception of health}

In order to gain insight into ways that black males with schizophrenia view themselves, with regard to their health, the investigator referred to the following studies. These studies looked at the perceptions that African American males have about their physical and psychological health. There is a noted absence of studies that look particularly at mental health issues therefore these are presented to provide potential insight to the researcher. The first, conducted by Ravenell, Johnson, and Whitaker (2006) indicated that black males have a very broad view of health, and that psychological stress is an important health issue for them. The researchers reported that African American males stated that racism was a major stressor that negatively impacted them physically and mentally.

A second study investigated the extent to which African American males identify with each other in developing attitudes about health and illness (Wade, 2008). The author reported that the more that a study participant identifies himself as being like other African American males, the more likely he was to engage in healthy lifestyle behaviors. An individual, who viewed himself as different from other males, became isolated and was unlikely to maintain healthy lifestyle behaviors. Also, this isolated individual was reluctant to seek treatment for illness. I suspect these findings will be relevant to the attitudes of African American males diagnosed with schizophrenia with respect to this group's view of their own condition.

In another study, Cheatham, Barksdale, and Rogers (2008) reported unique barriers that African American males face related to health care, as described by these 
men. The self-identified barriers include: socioeconomic status; low paying jobs with no health benefits; impaired masculinity; perception of not wanting to be perceived as weak; lack of awareness of need for care; racism and mistrust of the medical establishment; religion and spirituality including illness viewed as punishment from God; criminal background; difficulty obtaining employment and therefore inability to pay for health care. Each barrier taken alone was not exclusive to African American males, however the entirety of the list made for overpowering hindrances. An important finding was that family, friends and neighbors were viewed as positive influences. The men stated that they were more likely to seek care if a female member of the family suggested it.

\section{Role of family}

In a study conducted by Weisman, Rosales, Kymalainen, and Armesto (2006), with families of various backgrounds found that in White and Latino families, there was congruence between the relatives' expressed criticism and the perceptions of schizophrenic patients. However, among Blacks no significant association was found between relatives' expressed criticism of the patient and the patients' perceptions of their relatives' criticisms. Some of the reasons suggested for these findings included the idea that what appears to be criticism to an observer from another ethnic group is not viewed as such by the black person diagnosed with schizophrenia, and therefore is not experienced as stress related to the criticism. A limitation of the study was that the construct of perceived stress by the patient was not measured.

In another study, involving African American patients diagnosed with schizophrenia, high levels of relatives' critical and intrusive behaviors were associated 
with better outcomes, whereas for white patients the reverse was found. That is, with this cohort of white patients, low levels of both relatives' critical and intrusive behavior were associated with better outcomes (Rosenfarb, Bellack, \&Aziz, 2006). It was postulated by the authors that this form of behavior by the African American family was considered engagement and thus represented caring and concern. These studies suggest cultural differences in what constitutes family support as viewed by persons with schizophrenia. This difference in perception may influence how the individual views his own illness and what, in his mind, constitutes helping behaviors. The beliefs held by family members of African American males diagnosed with schizophrenia about the causes of that condition has an impact on the larger culture. The family often provides the primary support for these men and, in turn, may play a pivotal role in treatment decisions.

According to Esterberg and Compton (2006), 86.2 \% of African American family members of individuals hospitalized for schizophrenia endorsed a biologic etiology of schizophrenia. The authors state that the major findings in the reported causes may be related to the fact that the family members were influenced by the mental health professionals who were providing treatment to their relative. Along with the endorsing the biologic causes of schizophrenia, over $50 \%$ of the sample also reported belief in at least one esoteric or arcane cause. Possession by evil spirits and environmental pollution were the most common responses. The seeming incongruity of the family support system's simultaneous belief in scientific and non-scientific explanations for the affected member's disease process reflects the importance of 'culture' in informing the nature of this mental health condition (Carpenter-Song, 2009). 


\section{Recommended treatment for schizophrenia}

To refine the treatment of schizophrenia the Agency for Healthcare Research and Quality (AHRQ) reported recommendations for the treatment of schizophrenia developed by the Schizophrenia Patient Outcomes Research Team (PORT) (Lehman \& A.F. et al., 1995). The proposed categories of interventions were:

1. Antipsychotic medication.

2. Adjunctive pharmacotherapies for anxiety, depression, and aggression/hostility.

3. Electroconvulsive therapy (ECT).

4. Psychological interventions.

5. Family interventions.

6. Vocational rehabilitation.

7. Assertive community treatment/assertive case management.

In 1998 when the PORT measured compliance with the recommendations for treating schizophrenia, it documented considerable shortfalls in treatment adequacy, including detecting significant racial disparities, between the years 1994 and 1996 (Lehman et al., 1998) . In a study that assessed oral outpatient dosing patterns and psychotropic treatment of Medicaid-insured individuals, age, racial and gender disparities were noted (dosReis, Zito, Buchanan, \& Lehman, 2002). Findings by these investigators indicated that young adults, males, and African Americans were given high-potency antipsychotic medications at outpatient maintenance doses that exceeded the maximum recommended levels, despite well-established evidence that high-dose treatment offers no 
additional benefit. In addition, concurrent anti-Parkinsonian treatment exceeded the 1990 World Health Organization recommendations.

\section{Experience of Schizophrenia}

In a study by Usher (2001) of persons, who were taking neuroleptic medications as their main treatment for schizophrenia, several themes emerged. These themes included; hope for recovery, learning to live with the side-effects, embodiment of illness, experiencing issues of control, and struggling to stay well. Similar subjective experiences were reported in other studies as related to recovery from the perspective of individuals living with schizophrenia (Beebe, 2009; Jenkins \& Carpenter-Song, 2005). Watts and Priebe (2002) noted that persons being treated for severe mental illness (mainly individuals diagnosed with schizophrenia) felt that their voices had not been listened to with respect to their treatment interventions. Individuals cited in the studies alleged that the treatment interventions provided were coercive and attacked their very identity.

Jarosinski (2006) in a phenomenological study that focused on the experience of living with hallucinations for a group of adults diagnosed with schizophrenia and schizoaffective disorder identified four themes within the context of these individuals' sense of self. The themes were: Are they who they are? A not so certain life; Finding strength in broken places; and I am still me. The clients described thoughts of "being made to feel different" from other people, and "feeling separate". The hallucinatory experiences contributed to the individuals' feelings of powerlessness and sense of being resigned to their fate 
In a work comprised of qualitative analyses of first person narrative accounts of 100 men and women living with schizophrenia, Davidson (2003) related factors that contributed positively or negatively to the recovery process in this condition. According to the respondents in the study, two major reasons that moved them toward recovery were related to their feeling accepted and valued by others and their being successful in efforts to accomplish everyday activities. The ethnic make-up of the participants was not given, so determination of the number of African American males included could not be determined.

\section{Conclusion}

In this chapter, a review of the extant literature yielded studies addressing Racism as related to health disparities; Impact of subgroup culture on perception of diagnosis of schizophrenia; Role of family, Recommendations for treatment of schizophrenia; and Experience of Schizophrenia. These topics guide this investigation of African American males diagnosed with schizophrenia. These prior studies form the essential underpinning of this researcher's investigation into subjective views of the significance of this mental disorder from the perspective of individuals carrying this diagnosis. Although, phenomenological inquiries that examine the lived experiences of individuals diagnosed with schizophrenia have been conducted, none of these has focused exclusively on African American males. A major question left unanswered is, whether the experiences reported concerning persons with schizophrenia are reflective of African American males, exclusively. If African American males diagnosed with schizophrenia have unique 
experiences different from other groups, then what implications are there then for current and future mental health practices, policies and research studies? 


\section{Chapter 3}

\section{Methods}

\section{Introduction}

The purpose of this qualitative study was to understand and explore the meaning that schizophrenia has for an African American male. The inquiry was designed to answer the research question: "For African American males diagnosed with schizophrenia, what is the experience of living with this disorder?" The purpose of this chapter is to outline the design, procedure, data generation, and data analysis of this study.

In my practice as an experienced psychiatric nurse, who also is African American, I regularly make clinical observations about this male subgroup of persons diagnosed with schizophrenia. Originally, I planned the topic of my study to be the examination of medication adherence in this population. In caring for mental health patients, I have frequently mused, wondered and asked myself in frustration, when dealing with a recalcitrant patient "Why don't you just take the medication?" Now, I cringe at the built in bias and naiveté that is embodied in that question, which is in actuality the assertion that "you should take that medication, as I know what is best for you." What motivated me to form this opinion was the fact that I had seen the suffering in these patients, their isolation, the confessed fear, and their acknowledged desire to live a life of love, meaning and peace; things that I, myself sought. But instead, these men often lived lives that to me seemed loveless, lacked meaning and were chaotic. Thus, I had judged their lived experiences and viewed them as less desirable. 
A more useful question might have been "what is it like to live with this illness?" This became a central question asked in this study. From their answers to this query, I hope to gain clearer insight from the study participants of the nature of their condition. This improved understanding, I am convinced, will permit me to facilitate more appropriate care and achieve better clinical outcomes. After much introspection and exploration of my assumptions about the perceived unattractive aspects of the lives of these men, I have recognized that such a view is narrow. Previously, I have not systematically inquired of an African American male with schizophrenia, how he experiences his life, nor investigated the knowledge of his condition that he possesses.

The worldview that is guiding this inquiry process includes my general belief that persons with mental illness are the true experts on this phenomenon, and likewise African American males diagnosed with schizophrenia are the experts who possess the most reliable knowledge about their condition. The theoretical framework that has informed my thinking is existential phenomenology. It is my conviction that the situated context of their "being-in-the-world" (Heidegger, 1962) is accessible and can be clearly articulated by these men. However, to arrive at this conclusion, I had to acknowledge my own biases and assumptions. Based on past clinical interactions, my assumption is that the participants will be comfortable and willing to share this experience with me. I have worked frequently with African American males on inpatient psychiatric units and consistently have been successful in interacting with this patient group, as indicated by achieving excellent medication adherence results, experiencing exceptional cooperation in the patient-nurse interface, and in maintaining acceptable unit decorum. A final 
assumption from my experience is the possibility that my gender may have an effect on the interaction between me and the study participants (Kelly \& Greene, 2010). However, in acknowledging this potential limitation, I have observed that the nature of the relationship and the quality of the communication between the client and me will have the greatest impact on the quality of the interactions. This assumption is supported by the work of Peplau $(1952,1987)$, who emphasized the nurse-patient relationship as the foundation of nursing practice. Peplau's approach shifted the focus from what nurses do to patients to what nurses do with patients, thus creating the interpersonal relational model of nursing practice (Varcarolis \& Halter, 2010).

I have selected interpretative phenomenology as the method to investigate the meaning of the experiences of the African American males. Interpretive phenomenology is the qualitative design that is congruent with exploring, understanding, and interpreting the topic of interest. In that spirit, the following question is posed, "For African American males diagnosed with schizophrenia, what is the experience of living with this disorder?" According to Creswell (2007, p. 57):

"a phenomenological study describes the meaning for several individuals of their lived experiences with a concept, or a phenomenon. He further states that the basic purpose of phenomenology is to reduce individual experiences with a phenomenon to a description of the universal essence."

Hermeneutic phenomenology is oriented toward interpreting the texts (narratives) in addition to describing the lived experience (van Manen, 1990). According to Madjar and Walton (1999), phenomenology offers the possibility of studying human experience in the context of the lifeworld. In the planned study, this unique experience can only be 
expressed by the individuals with schizophrenia telling their specific stories in their own way.

\section{Phenomenology}

Phenomenology is the study of structures of consciousness as experienced from the first-person point of view (Stanford Encyclopedia of Philosophy, 2008). It is considered a philosophy, a perspective, and an approach to practice and research (Munhall, 2007). In van Manen's construction, phenomenology is concerned with the study of the individual's life-world, as experienced rather than conceptualized, categorized, or theorized. Phenomenological research is the study of essences (van Manen, 1997, p.10). I will use interpretive phenomenology based on van Manen's work to inform this investigation.

For the conceptual understanding of this study, the phenomenological and existential philosophers that I found to have influenced van Manen's hermeneutic phenomenology are; Edmund Husserl (1859-1938), Martin Heidegger (1889-1976), Maurice Merleau-Ponty (1908-1961), and Hans-Georg Gadamer (1900-2002). van Manen's method is selected for this study of the lived experience of African American males with schizophrenia, because he combines what I believe are valuable elements of all the above named philosophers. This amalgamation, in my view, will add depth and richness to the data analysis and final written narrative of the study.

Edmund Husserl, the European philosopher, is credited with the introduction of the concept of phenomenology (Luijpen \& Koren, 1969). Husserl, a mathematician, called himself a positivist, and embraced Cartesian duality, the model of the mind and the 
mind-body split. This approach contributed to his having a mechanistic view of man (Koch, 1995). Husserl asserted that empiricists were incorrect in their view that all knowledge must be grounded in experience, and therefore obtained from sense data (Walsh, 1996). Concepts associated with Husserlian phenomenology include 'life-world' or 'lived experience'. According to Husserl, these experiences are not readily accessible, because we take them for granted when they are occurring; therefore, we must reexamine them to obtain the essences. Essences constitute the consciousness and perception of the human world, and Husserl declared that phenomenology should be descriptive psychology of consciousness, which would 'return things to themselves' (Koch, 1996). According to Husserl, intentionality, or relatedness is the principal subject of phenomenology (Munhall, 2007). Crotty (1998) explains intentionality as follows: "When the mind becomes conscious of something, when it 'knows' something, it reaches out to it and into, that object" (p. 44).

Bracketing is another Husserlian concept. Under Husserl's methods of inquiry, all preconceived notions are to be set aside. It is not a matter of saying that they do not exist, but rather of refraining from judgment by disconnecting from the idea or belief. Through this process of bracketing, one can defend against claims of lack of objectivity of interpretation and self-interest of the researcher (Koch, 1995).

Martin Heidegger focused his work on ontology, the study of being. For Heidegger, philosophy is ontology, and ontology is phenomenology (Crotty, 1998). A student of Husserl, this philosopher did not subscribe to his teacher's Cartesian philosophy. Heidegger formulated the concept of Dasein. Dasein is a term that refers to 
an aspect of our humanity, which is capable of wondering about its own existence and inquiring about its own Being (Heidegger, 1962; van Manen, 1990). Heidegger is credited with developing hermeneutic phenomenology (Dowling, 2005; Heidegger, 1962). Two major ideas are that attributed to Heidegger are the historicality of understanding and the hermeneutic circle (Heidegger, 1962, Koch, 1995). These concepts are supported by the Heideggerian concepts of background, pre-understanding, co-constitution, and interpretation. Background is what a person gets from his culture when he is born and presents a way for him to understand the world. Pre-understanding is the meaning and organization of the culture that is with us, even before we understand. This includes language and practices of our particular culture. Co-constitution refers to the concept that we are being constructed by the world, while at the same time we are constructing that same world from our own experience and background (Koch, 1995). Therefore, any perceived division between an individual and the world is considered false by Heidegger. Hence, in his view, there is an unbreakable unity between the person and the world. One cannot have a world or a life at a cultural level, except through acts of interpretation, according to Heidegger (1962). In Heideggerian philosophy, understanding is a mode of being-in-the-world, not merely a way of knowing (Heidegger, 1962; van Manen, 1997).

The hermeneutic circle, as presented by Heidegger, is composed of the concepts of background, co-constitution and pre-understanding using the terms Being, Dasein, forestructure, and existentials (Koch, 1995, p.831). Heidegger further describes a circle of understanding as "not an obit in which any random kind of knowledge may move; it is 
the expression of the existential forestructure of Dasein itself" (1962, p. 195). All claims to understanding are made from a given set of fore-structures which cannot be eliminated, but only corrected and modified (Koch, 1995, p. 832).

Maurice Merleau-Ponty was influenced by Husserl and Heidegger and was an associate of Sartre. As a phenomenologist, Merleau-Ponty contributed to the concept that perception plays a major part in understanding the world and in engaging in the world (Stanford Encyclopedia of Philosophy, 2004). van Manen, on referencing Merleau-Ponty related to intentionality, quoted him as stating that the world that is revealed to us is "ready-made" (van Manen, 1990 p.182). Merleau-Ponty used the phrase that the world is 'always already there' in much of his writing (Crotty, 1998, p.44). The concepts that consciousness consists of sensory awareness of and response to the world and knowing the world is possible only through subjectively being-in-the-world are major contributions found in the work of Merleau-Ponty (Munhall, 2007).

Hans-Georg Gadamer, a student of Heidegger, built on Heidegger's work, known for informing hermeneutic phenomenology with the concepts of prejudice, the fusion of horizons, the hermeneutic circle and play (Gadamer, 1976; Walsh, 1996). Prejudice is a judgment that is made before all the elements that determine a situation have been examined (Walsh, 1996). For a researcher investigating a phenomenon for which he has firsthand knowledge, that individual uses his pre-understandings and fore-meanings to come to a preliminary understanding of the responses provided in the narrative by the participants. The fusion of horizons means that the horizon of the present is continually in the process of being formed, because prejudices are being tested. Hermeneutic circle is 
the process of interpretation that occurs in a circular fashion. Within this construct, our horizons of understanding are happening in a dynamic way. An example of how the hermeneutic circle and horizon of understanding work is found in how language is used, learned and understood (Walsh, 1996). As it relates to interpretation, Gadamer does not use objectivity or subjectivity as frames of reference, but rather thinks of himself as a player in a game. He refers to the necessity of spontaneity and movement in expanding the horizon of understanding, thus avoiding the fruitless subjective-objective distinction (Gadamer, 1976).

Max van Manen brought his educator background to hermeneutic phenomenology by providing his instructive text to research (van Manen, 1990). He describes the interpretative approach to understanding as textual reflection on the lived experiences and practical actions of everyday life with intent to find meaning and greater essences of significant aspects of human existence (van Manen, 1990). Like Heidegger, van Manen does not embrace Husserl's view of bracketing and inquires; "If we simply try to forget or ignore what we already 'know', we might find that the presuppositions persistently creep back into our reflections" (van Manen, 1990, p. 47). As a method of inquiry, van Manen's human science approach emphasizes the connectedness between the viewpoints of the researcher and those of the study participants, thus enhancing the understanding between the two.

Lived experience, as described by van Manen (1997), involves the individual's immediate prereflective consciousness of life. "Phenomenology appeals to our immediate common experience in order to conduct a structural analysis of what is most common, 
most familiar, most self-evident to us" (1990, p. 19). With van Manen, the combination of interpretative and descriptive elements is summed up as follows: "phenomenological text is descriptive in the sense that it names something and hermeneutic text is interpretive in the sense that it mediates" (van Manen, 1997, p. 26). Phenomenology tries to distinguish what is unique, or the essence of the phenomenon, to better understand what the particular experience is like (van Manen, 1990).

In order to understand the meaning of living with schizophrenia for African American males, I will use the four fundamental existentials described by van Manen (1997), as permeating the life worlds of all human beings. The four concepts are: lived body, lived space, lived time and lived human relations. According to van Manen (1997), these four existentials can be differentiated but not separated.

Lived body relates to how a person is corporeally or physically present in the world, and it is by this physical appearance that he meets other people (van Manen, 1997). van Manen proposes that when we are ill, 'everything seems to be too much, too difficult, too cumbersome. Quite literally, the world has become sick' (van Manen, 1998, p. 11). In a discourse on man bodily being, Luijpen said that, "when my body disintegrates, my world also 'goes to pieces,' and the complete dissolution of my body means a break with the world" (Luijpen\& Koren, 1969, p.36).

In her phenomenological work on the lived experiences of men and women with schizophrenia, Walton (1999) wrote that the participants reported altered bodily manifestations due to the illness. The participants, who were diagnosed with schizophrenia, talked of a tiredness or difficulty in commencing and completing tasks, 
that no matter how much they wanted to engage in a particular activity, they could not do so. This "difficulty propelling their bodies into the world" consistently interfered with their ability to work and to engage in recreational activities (p.113). Participants stated that they recognized that tiredness or sleepiness were side effects of their neuroleptic medications, but were reconciled to continuing the medication, out of necessity. Walton (1999) noted further that to the people in her study, "taking regular medication becomes a part of their Being-in-the-world" (p. 115).

van Manen describes lived space as "felt space" or "the nature of lived space that renders that particular experience its quality of meaning" (van Manen, 1997, p.102). This concept may be related to the way the individual feels about his environment and his perceived power to design his world. This concept can include changes that African American males diagnosed with schizophrenia make to in order to accommodate their mental health treatment.

Lived time refers to the how time is perceived or experienced by the individual. This can include the appearance of the duration of a lived experience and its orientation to present or past events. Lived time in the context of a chronic disorder, such as schizophrenia, can arouse feelings of uncertainty as to how illness will affect future life (Thome et al., 2004).

van Manen (1997) defines lived human relations as follows: 'through lived relation to others we maintain with others in the interpersonal space that we share with them' (van Manen, 1997, p.104). Because participants in this study are living with the condition of 
schizophrenia, this disorder can involve limitations or redefinitions of the individual's role in life.

\section{Design, Sample}

Design. A hermeneutic phenomenological research approach as described by van Manen (1990) was selected to guide this study. Phenomenology as a method is well suited for studying lived experience. A phenomenological study describes the meaning for several individuals of their lived experiences of a concept or a phenomenon (Creswell, 2007). Consistent with this view, the study participants who have been diagnosed with schizophrenia are the only voices that can speak of what it is like as an African American male to be diagnosed with this serious mental illness.

Sample. The participants for this study were African American males who were diagnosed with schizophrenia. Given the nature of this hermeneutic phenomenological inquiry, the men were aware that they had been diagnosed with schizophrenia. The criteria for inclusion in the study included: ability to speak and understand English; 18 years of age or older; living independently in the community; able to consent to participate based on outpatient staff's assessment; and having the ability to articulate his story. A critical exclusion criterion was a diagnosis of primary dementia, because this condition may interfere with the participant's abstract thinking that may already be diminished due to schizophrenia. The presence of dementia was determined by the use of the clock drawing test administered by the investigator (Ismail, Rajji, \& Shulman, 2010; Nair et al., 2010), at the time candidate agreed to participate in the study. Individuals who 
were unable to draw a clock the indicating the time instructed by the researcher were not included in the sample.

Five participants were recruited from outpatient psychiatric clinics in the Greater Richmond, Hampton/Newport News, and Williamsburg, Virginia areas after sampling saturation was reached.

\section{Procedures}

The recruitment approach consisted of two components. The first component involved using flyers (Appendices A \& B) affixed to bulletin boards of business and community centers, outpatient facilities, and electronically provided to psychiatric clinical professional and mental health organizations in the Richmond and Hampton/Newport News areas. Individuals then distributed the flyers to clients that they believed might be appropriate candidates. The flyers were a short description of the research study, along with contact phone numbers and the investigator's institutional email address. Interested candidates used the flyer information to contact the researcher. The second recruitment method involved information sessions. These information sessions were provided at the participating mental health organization's weekly or monthly meetings. During the information session flyers were made available. The nature of the study was explained and interested individuals were provided the opportunity to ask questions. Flyers were left at the site so that further information could be given as necessary. Interviews were conducted at mutually agreed upon times at the outpatient clinics sites. That environment facilitated confidentiality for the participant and privacy. At the time of the interview demographic data were collected by the researcher. As 
compensation for the time and effort given to the study, each participant was provided a $\$ 20$ card. One participant was referred to the study by his case manager, the other four respondents were self selected as a result of seeing the recruitment flyer and participation in recruitment presentations given by the researcher.

\section{Data Generation}

Following informed consent, in-depth, face-to-face audio taped interviews were conducted with each of the participants in a room that ensured privacy and safety, comfort for the interview process (size, furnishings, lights, temperature), and using technical equipment possessing acoustical properties that resulted in audiotapes suitable for verbatim transcription. One hour was set aside for each interview, but the interview was considered complete when the individual stated that he had nothing to add to his responses or indicated that he wished to terminate the interview. Small unopened bottles of water were available for participants.

Although van Manen recommends multiple sessions, the investigator conducted only one interview. Additional interviews would have increased participant burden while likely not adding to the data. There was a high likelihood that this population would neither consent, nor return for another interview based on the history of logistical issues that had been identified. These included but were not limited to lack of transportation, next scheduled appointment 3-6 months, or other difficulties related to access (Beebe, 2010).

The very nature of phenomenological questioning made it difficult to design a structured questionnaire, because questions emerge and are derived as the understanding 
of the phenomenon emerges. However, in using van Manen's (1990) method, he pointed out that the "interview process needs to be disciplined by the fundamental question that prompted the need in the first place" (p. 66). He suggested that often researchers give in to the temptation to " let the method rule the question rather than the research question determining what kind of (interview ) method is most appropriate for its imminent direction" (p. 66). To give focus to the interviews, six inquiries were posed to serve as a general interview guide.

1. When and how did you learn about your diagnosis of schizophrenia?

2. Tell me about a typical day.

3. What has been your family's reaction to your diagnosis? Your community's response?

4. What has been your experience with psychiatric or mental health treatment?

5. Have you had any particular challenges with schizophrenia being an African American male?

6. What would you like people to say about you?

In addition to taped-recorded interviews, detailed field notes and a methodological journal were maintained and documented immediately after each interview, to keep track of observations, decisions, feelings, and thoughts about the interview process and content.

\section{Data Analysis}

The data were analyzed using components of van Manen’s (1990, 1997) methodological approach which addressed both description and interpretation. The audio 
tapes were transcribed verbatim and a thematic analysis conducted by reflecting and intuiting on the contents of each of the transcripts. Next a selective reading approached was used. Significant statements and key words were noted, as the individual transcripts and themes were examined in light of all the transcripts. Line-by-line reading of each transcript was performed and meanings were noted within each statement in relation to the text as a whole. Using this process, general themes emerged that crossed the data. The investigator's field notes that were recorded after each interview were considered in the analysis. The data were reported as narration of the 'essence' of the experience in written discussion and tables.

Specific steps in the procedure for data analysis were clearly outlined in the Methodological Structure by van Manen in his (1990) publication:

1. Assume a phenomenological style of thinking and orienting; that is, outline personal assumptions and pre-understandings and adopt an attitude of reflective attention to lived experience.

2. Conduct audio-taped interviews to obtain experiential narrative descriptions from the participants as a source for developing understanding of the phenomenon.

3. Transcribe the interviews into text; read each interview while listening to the audiotape in order to validate accurate transcription of data.

4. Use a coding procedure to enable identification of text that is relevant to the phenomenon of interest; material that is irrelevant will be deleted from the working document. 
5. Conduct a reflective thematic analysis of each interview; that is, uncover essential thematic aspects in each narrative text by (a) multiple readings and reflection on the text in its entirety, (b) selective reading of text for significant statements and phases, and (c) detailed line by line reflective examination of the text. Field notes, journal entries, and related literature will be used as data to increase insight.

6. Interpret meanings within the text data by using an iterative reflective process of reading and reflection, considering parts and whole (hermeneutic spiral).

7. Read text across participant interviews to confirm common essential themes and shared meanings.

8. Communicate an interpretive understanding of the phenomenon in the writing of a phenomenological narrative. The ending anecdotal narrative reflects many different stories of meaning, while outlining similarities and differences, as well as, common patterns, themes and discoveries.

The approach that was used in order to accommodate these steps was as follows:

1. Listed assumptions that will be reviewed prior to the initial interview.

2. Shared other assumptions, as they evolve, with members of the dissertation committee.

3. Kept field notes as part the audit trail; along with interview data, field notes will be used to inform the findings. 


\section{Data Management}

Audio-taped data, were transcribed immediately after the interview was conducted. Following transcription, each transcript was reviewed and prepared for data analysis. Subsequent to analysis, de-identified data (audiotapes and transcripts) were stored in a locked file cabinet to be retained for 3-4 years, and then destroyed according to the requirements that are outlined in the IRB human studies protocol.

\section{Trustworthiness of the Data}

The four concepts proposed by Lincoln and Guba (1985) for establishing rigor, or trustworthiness of the data, are credibility, transferability, dependability and confirmability. Credibility is comparable to truth value (Sandelowski, 1986), when the descriptions or interpretations of a phenomenon are such that people who have had the experience would recognize it as their own, while the experienced would recognize that same occurrence after having read about it in a qualitative study. The researcher used the following operational methods to achieve credibility; (a) purposeful sampling, (b) audiotaped interviews, which are transcribed verbatim, (c) peer debriefing/critique after each interview, and (d) maintenance of an audit trail (Lincoln and Guba, 1985). Transferability or applicability (Sandelowski, 1986) occurs when the study's findings are seen as meaningful and 'fit' the data from which they are obtained and are well grounded in the life experiences reflected. In addition, these findings 'fit' into contexts outside the research study. The operational techniques that the investigator used to assure transferability are (a) purposeful sampling, and (b) writing 'thick', 'rich', narrative description in presentation of the findings (Lincoln and Guba, 1985). After data were 
collected and analyzed from four interviews, analysis was conducted by a non-psychiatric nurse expert to audit researcher's procedures. Hermeneutic conversations and peer review were held with a psychiatric expert in the field of schizophrenia and phenomenological inquiry in order to facilitate authenticity of interpretations regarding the experiences. The third criterion for determining rigor or trustworthiness using the Lincoln and Guba approach is dependability, which refers to the consistency of the qualitative inquiry's findings. The study and its findings must be auditable so that another researcher can clearly follow the documentation of the decisions made by the primary investigator. The operational techniques that the researcher used were (a) peer review and, (b) maintaining the detailed audit trail.

The final criterion is confirmability, which is comparable to what Sandelowski (1986) referred to as neutrality. Confirmability is achieved when auditability, truth value and applicability are established. The concept refers to the research findings themselves, not to the objective or defensive stance of the researcher (Lincoln and Guba, 1985). By establishing and maintaining that comprehensive audit trail, the study will exhibit confirmability.

In order to reveal and scrutinize the influence that my assumptions have on the investigation, the investigator used reflexive journaling. Journaling as a method of bracketing contributes to rigor in phenomenological research (Munhall, 2007). The researcher wrote periodically in a notebook her thoughts, reflections and biases. Along with these, she included her research related schedule and a methodological log. The investigator also collected in a loose leaf binder, emails that she sent to her Program 
Director, members of the dissertation committee, and the peer reviewer/debriefer related to the study. The researcher participated in several meetings with dissertation advisors and members of her committee to facilitate confirmability or neutrality. 


\section{Chapter 4}

\section{Findings: The schizophrenia experience}

\section{Introduction}

Through interpretive phenomenology, this research aims to enrich our understanding of living life with schizophrenia for African American males. There is no single method for conducting interpretive phenomenology. The researcher holds to the following "the purpose of phenomenological reflection is to grasp the essential meaning of something" (van Manen, 1997, p 77). Essential themes are aspects or qualities that make a phenomenon what it is, without which the phenomenon could not be what it is (van Manen, 1990).

\section{Thematic analysis}

Employing a methodological structure by van Manen (1990, 1997), the digital audio recordings were transcribed into verbatim text. Using these texts a thematic analysis was conducted by reflecting upon and intuiting the contents of each of the transcripts. Next, a selective reading approach was used. Significant statements and key words were noted, as the individual transcripts and themes were examined in light of all the transcripts. Line-by-line reading of each transcript was performed and meanings were noted within each statement in relation to the text as a whole. Using this process, general themes emerged that cross the data. The investigator's field notes recorded after each interview were considered in the analysis. The verbatim transcripts were made available to the hermeneutic team via email. The researcher's field notes and initial readings of the 
narrative were presented in face to face meetings with the other team members. The hermeneutic team was comprised of the nurse researcher, a $\mathrm{PhD}$ psychiatric qualitative research nurse expert and an expert in schizophrenia and phenomenology inquiry. The interview narratives were read in their entirety by the team to achieve overall understanding. Members of the team then identified related themes within the interview. The transcripts were read and reread and organized into evolving themes. Some themes were eliminated, while others were clarified. Emails were exchanged, face-to-face conversations held, and telephone calls made to identify implicit and explicit meanings from the interviews so as to facilitate authenticity of interpretations regarding the essence of the reported experiences. Consensus occurred as themes were discussed and we arrived at inter-subjective agreement about the fittingness of the themes with the text. Variances in interpretation were discussed and documentation from the texts was used to support the choice of relational themes. An important goal of this method is to identify a requisite pattern in the narratives that shows the association of the relational themes. An opportunity for review of the entire analysis was provided to all members of the team. Also, a non-psychiatric doctoral student peer was consulted for debriefing session within two days after each interview in order to review the process and identify possible biases. As a result of the above steps, four essential themes emerged:

- They know that they are mentally ill

- They make a special effort to test reality

- They assert their autonomy

- They experience reality differently, which they see as a gift 


\section{Demographic data}

After informed consent was obtained and the candidate was able to successfully draw a clock, a brief demographic survey was conducted by the researcher with each participant. The information provided is outlined in Table 1.

Table 1 Demographic information

\begin{tabular}{|c|c|c|}
\hline Age & Range & $21-57$ \\
\hline & Mean & 41 \\
\hline \multirow{2}{*}{ Marital Status } & Divorced & 1 \\
\hline & Single( never married) & 4 \\
\hline \multirow{4}{*}{ Education } & $7^{\text {th }}$ Grade & 1 \\
\hline & High School Graduate & 2 \\
\hline & Associate Degree & 1 \\
\hline & Bachelors Degree & 1 \\
\hline \multirow{2}{*}{ Employment } & $\begin{array}{l}\text { Part-time( partial } \\
\text { disability) }\end{array}$ & 1 \\
\hline & Disability (unemployed) & 4 \\
\hline \multirow{3}{*}{ Current Treatment } & $\begin{array}{l}\text { Psychiatrist (medication } \\
\text { management) }\end{array}$ & 5 \\
\hline & Case Manager & 2 \\
\hline & Peer Support Group & 4 \\
\hline \multirow{5}{*}{ Medications } & Neuroleptic & 5 \\
\hline & Antidepressants & 1 \\
\hline & Anti anxiety & 1 \\
\hline & Antiparkinsonian & 2 \\
\hline & Anti-Hypertensive & 1 \\
\hline \multirow[t]{2}{*}{ Age when diagnosed } & Range & $13-33$ \\
\hline & Mean & 21 \\
\hline
\end{tabular}

$\mathrm{N}=5$

The participants were all African American men. Their ages ranged from 21 to 57

years, with a mean age of 41 years. Four of the men had earned a high school diploma; 
one had completed the $7^{\text {th }}$ grade; one had earned a Bachelors; one an Associate Degree. All of the participants were receiving some form of disability payment. All of the participants were single at the time of the study with four that never married and one that was divorced. All were currently receiving psychiatric outpatient care and were taking some type of neuroleptic medications. All the participants were adherent to their treatment regimes. All five of the candidates who initially volunteered for the study were retained in the sample. The age at the time of the initial diagnosis of the schizophrenia ranged from 13 to 33 years with a mean of 21 years. All the participants had been diagnosed with schizophrenia for at least two years.

\section{Context of the interviews}

Participant \# 1- Anthony

Anthony is a 29 year old thin, earnest appearing man of medium height, neatly attired with a fixed penetrating stare. He appears younger than his stated age and speaks slowly and deliberately. His gait is stiff and cautious. He studied the consent form carefully and asked about the section that indicated that participation in the study may not be of benefit to him. He indicated that he thought that meant that he would not receive the \$20 gift card. When it was explained that was not the meaning, he seemed to relax. Anthony reports that he had his first auditory hallucination in his early teens during a flight from Los Angeles to New York. He did not disclose the content of those voices. Since that time, he states that he hears voices and reports experiences like, Birds, and cats talking like humans. He told the interviewer "I had a cat that said, "mama I love you." 
He also reports -“I see things that others possibly don't see. I believe that a certain, or almost every channel on TV, including the radio is talking to me."

He requested that he be allowed to read from a piece of note book paper to describe his experience. He read some of the following:

(I note) hesitations by everyone I see or meet and on TV or radio (that) make(s) me to think that they can read my thoughts. These constant auditory hallucinations make me think that this is the reason why people know everything about me and people can read my thoughts.

According to Anthony, medication helps somewhat, but does not completely eliminate his symptoms. He reports being hopeful that the new medication regimen that he has recently begun will result in more improvement. At one point in the interview he asked me, the researcher, if I could read his mind. He relaxed noticeably when I stated that I could not. He told me that he had asked his case manager, counselor and psychiatrist the same question and they had also stated that they could not read his thoughts.

He describes himself as a nice person, polite, and respects everyone. He adds "I don't want people to think that I'm abnormal (any) more than anybody else is." Participant \# 2- Darius

Darius is a 52 year old, tall, muscular-built bald man who looks like a Masai warrior. When he speaks, his eyes soften; he laughs easily thus changing his appearance to one that is less imposing. He states that he spends several hours daily at the community gym in order to maintain his physique and overall general health. He reports having a Bachelors degree in physical education. When asked about how he learned of his 
diagnosis of schizophrenia, he states "like I say, I was using different kinds of substances and doing a lot of drinking and he (a psychiatrist) gave me the diagnosis then." Darius was about 33 years old at that time. About his treatment, especially medication he states “it keeps me balanced, it keeps me focused. It keeps me.... it keeps my feet on the ground also. And ... without it I don't where I'd be." Darius does not report any active symptoms of schizophrenia at this time.

He spends time as a peer counselor for others with mental illness within the NAMI organization. Concerning his experience with mental health treatment he replies:

My experience, you know, cause I've dealing with this for awhile is . . You know sometimes I be thinking about these therapists and these psychologists and psychiatric workers, you have to ask yourself .... and I'll be saying, ah... yeah I guess you got a lot of schoolin', you went to school and spent a lot of time in that field, but you are fortunate, cause I don't feel that you know more, I'm 52 and you not no smarter and no more intelligent than I am.

In terms of community response to his schizophrenia:

I have gotten to the point that, first of all, number 1, I don't care, and number 2 . . . I don't have to get along with you; I don't have to kiss your butt. And number 3 is, I'm my own person. And people are going to talk about you regardless, ah... you know and there's always ... you know that's ... that's another stereotype that people need to get rid of. But if you focus on it then that's your problem. Keep on moving.

Participant \# 3- Tyrone

Tyrone is 57 years old, tall, slightly stooped as he walks with a bear-like gait. He has graying hair and twinkling eyes. He sometimes sounds out of breath when speaking. I observed him smoking outside of the building when I arrived for the interview. His 
fingers have what appear to be nicotine stains, indications that he is a long time smoker. After making remarks that he intends to be humorous, he frequently laughs.

He arrives at the appointment early because a neighbor gave him a ride when the neighbor saw him walking. He reports that his neighbors sometimes invite him to picnics during summer holidays and another one drives him to his Alcoholic Anonymous Meeting. Tyrone was diagnosed with schizophrenia at age 20 when he was in the military. He recounts his experiences as "they, the VA started sending me a check and gave me a contract you know, saying I was schizophrenic. You know, I didn't understand what it was, or whatever, but I just know I had this contract and everything, that I would be receiving money for the rest of my life. And you know that is the first time I heard of schizophrenia, I've never understood it until now. I understand my illness now within myself."

Tyrone is divorced with two adult children, a daughter and a son. He states that his aunt and her daughter help him raise his children. His daughter, who has recently graduated from college lives with him and his female cousin, who is in the process of moving out. Tyrone says that he will miss her as she has taken good care of him, providing healthy meals and things like that. It is unclear why she is leaving, but he tells a convoluted story about conflict with his aunt and this same cousin surrounding the control of his veterans' pension and his ability to manage his own finances.

When asked how he spends his day he reports "I tell you I'm trying to find inspiration to get up the morning. You know I got all this time on my hands." He says 
that he used to work and enjoyed doing that, but has not done so for a few years, but he did not state why. He does say that he still goes and has morning coffee occasionally with his former employer, who has a landscaping business.

He believes that he has special abilities of prognostication.

And I saw Michael Jackson was going to die about 4 months before, you know, I can just look at the cards, I had to write it down, each card is an alphabet and a number to me. The number made the alphabet and the alphabet read out ... read out things with the alphabet and I saw that Michael Jackson was gonna die about 4 months before he died.

He reports that he made Richard Nixon resign his Presidency. He describes having schizophrenia as being special.

I just felt special cause, you know, having a vivid imagination, it takes up the time of the day for you. You know like, if I think awhile . . you know cause they say you only need a $12^{\text {th }}$ grade education to do and you could be anything in the world you want to be.

Participant \# 4- David

David is a 44 year old, tall, heavy-set, loquacious man whose size and presence literally and figuratively fill the small interview space. He reports only completing the $7^{\text {th }}$ grade because while he was in the $8^{\text {th }}$ grade, the principal told him that he could not return to school unless he received psychological testing. Rather than comply with that requirement, he quit school and went to work. He is not clear how old he was when this occurred but it sounds as if he were about 16 at the time. Nevertheless, he is articulate, expressing his thoughts in colorful language. He reports reading several books each 
week, which he borrows from the library and during our meeting he talked about some recent non-fiction works that he had read.

David reports his initial break as follows:

The first time I went into the hospitals like in 1989, I believe, shortly after I don't know ... losing my temper at home, I kind of destroyed the furniture in my room and my mother's home ... my sister, so they rushed me to the hospital and that night I stayed overnight. They ran some tests on my brain and stuff like that and it came back that I was paranoid schizophrenia.

He describes several hospitalization where he refused to shower and attend to his

personal hygiene to the point that the "nurses' body guards forced him to shower and take medication", while he was at Central State Hospital. He narrates that he requested medication that would fatten him up so that he would be better able to defend himself against the staff and other patients that would 'fight him'.

I haven't been in the hospital for 2 years. I've been out Central State now for the last 5 years and I've been living on my own for the last 5 years. So I'm doing pretty well. My medi ... My medication is stabilizing me to the point that I . . I I can concentrate better, I'm more focused, more goal oriented, but back before I did . . they got my medications stabilizing right, I was like destroying property, starting fights, picking fights with girls and women and I didn't care who's around. [I] Just want to start trouble and be [ing] inappropriate. Then maybe about the last two years they finally put me on the right meds, like all the bad stuff I did is no longer considered ... I [am] no longer am concerned with it. Because it's gone now, it's in the past.

During this time, David describes his mother, who has been through a lot with him, and his sister as supportive of him. Though he acknowledges that his mother 'suffered' but, he says that she understands because she is a nurse and a strong lady. David is in a program called "Friends for Recovery", that he reports gives him a structured lifestyle. 


\section{Participant \# 5- Paul}

Paul is a short, medium built, 21 years old who is soft-spoken and attentive. He wears wire-rimmed glasses that slip down on his nose as he talks. He has his hair arranged in neatly done corn braids. His attire consists of a tee shirt that contains the words "March to Washington to the White House" and pictures of Dr. Martin Luther King and President Barack Obama along with baggy jeans that he hold up with one hand as he walks. Paul reports having been diagnosed with schizophrenia two years ago. $\mathrm{He}$ describes the event as follows: "Some of the symptoms were ... hearing voices, and then like ... kind of like forgetfulness; you know ... not staying focused." He has been hospitalized three times since his initial break. Paul denies having any symptoms of schizophrenia at this time. He reports that the physicians have been "very supportive" as is his family. He states, “They accepted it and you know, they didn't criticize me; they just tried to help me; to encourage me to do it. You know, (they) made sure that I could still do what I was normally doing before, but now everybody's fine with it. They understand and don't criticize or nothing like that so." When asked if being African American and male pose any particular challenges to him as an individual diagnosed with schizophrenia, he responds, "Not. . not really. Ah ... Nope ... didn’t have any."

\section{Themes}

The four themes outlined below represent some of the aspects of the experience of being diagnosed and living with schizophrenia for five African American men. These particular themes were selected because they illustrate how these men view themselves, 
how they assess their world, and how they make decisions within the context of their mental illness. The participants were forthcoming in telling their stories. This willingness to be transparent on the respondents contributes to the richness of the text.

Table 2. Definitions of Overarching Themes

\begin{tabular}{|c|c|}
\hline Theme & Description \\
\hline $\begin{array}{l}\text { Theme } 1 \\
\text { They know that they are Mentally ill }\end{array}$ & $\begin{array}{l}\text { Able to identify and discuss the } \\
\text { symptoms of schizophrenia, for example, } \\
\text { delusions, and hallucinations. }\end{array}$ \\
\hline $\begin{array}{l}\text { Theme } 2 \\
\text { They make a special effort to test }\end{array}$ & $\begin{array}{l}\text { Sought clarification and additional } \\
\text { information by asking others or making } \\
\text { observation to determine if the thoughts and } \\
\text { belief was shared by them. }\end{array}$ \\
\hline $\begin{array}{l}\text { Theme } 3 \\
\text { They assert their autonomy }\end{array}$ & $\begin{array}{l}\text { Worked to establish and maintain } \\
\text { independence, decision making, and self } \\
\text { evaluation. }\end{array}$ \\
\hline $\begin{array}{l}\text { Theme } 4 \\
\text { They experience reality differently } \\
\text { [which they see as unique] }\end{array}$ & $\begin{array}{l}\text { Expressed the belief that they have the } \\
\text { ability to understand themselves and others at a } \\
\text { different level because of their illness that other } \\
\text { people do not have. }\end{array}$ \\
\hline
\end{tabular}


Table 3. Example of the revealing of one essential theme (theme 1) from narratives

\section{Holistic Reading Approach}

The illness means a time when the individual comes to recognize that his delusions and hallucinations are part of a symptom cluster that indicates a mental illness called schizophrenia that requires treatment.

Theme

Symptoms sometimes remain

Selective Reading Approach

'I see things that others possibly don't see.'

'Hearing voices, hearing auditory hallucinations, music, stuff like that.'

'Always thinking about something that's . . not bad, but not normal. You know like... just like the picture that we saw the man thought that the government was out to get him, I think like that sometimes.'

'I wasn't getting along with my roommate and I was just calling him the devil and everything'

Well sometimes I feel that it hasn't worked and they try different things, they try....I've .... Like I've tried a pill and it hasn't really helped and now I'm trying an injection on my arm. And that has somewhat helped.'

'Some of the symptoms were .... Hearing voices, ah.... (long pause) I forgot what else.'

\section{Writing and rewriting}

The person's unique experience of the phenomenon shows itself as ...experiencing sensory inputs that others in the environment do not to detect or have; therefore they are internal rather than external.

\section{Essential theme}

Symptoms sometimes remain

Presented in the overarching theme 'They know that they are mentally ill' 
Table 4. Example of the revealing of one essential theme (theme 2) from narratives Holistic Reading Approach

The illness means reality testing on the part of the individual to determine if others share his perceptions, thoughts, and beliefs

\section{Theme}

\section{Verification of situations}

\section{Selective Reading Approach}

'Hesitations by everyone I see or meet and on TV or radio make me to think that they can read my thoughts. Can you read my mind or know what's inside my head?'

'Cause I can't distinguish the real from reality, I mean the fake from reality sometimes. Sometimes it's kind of hard to distinguish the both of them, which is real and which is fake.

'I noticed I was dating this lady some years back and it was easy for me to recognize that she had mental health issues and she eventually told me, you know, she was bi-polar, she was this, she was that. But I already knew because of the way she was, she was up and down and always thought somebody was trying to do something to her and seemed like she had a problem getting along with other females too. You know, so, there's certain things that I can see in myself I can see in it in other people also.'

\section{Writing and rewriting}

The person's unique experience of the phenomenon shows itself as ...inquiring if others are experiencing sensory inputs, thoughts, similar to his own.

Essential theme

Verification of situations

Presented in the overarching theme 'They make a special effort to test reality' 
Table 5. Example of the revealing of one essential theme (theme 3) from narratives

Holistic Reading Approach

The illness means that there were times when the person may have conceded decision making, control of resources, or self assessment, to others, now has determination to take back that authority.

Theme

The importance of being accepted as he is

\section{Selective Reading Approach}

'I'm my own person. I'm not here to put on no airs, I'm not here to please nobody, I'm nobody's yes man, and I don't have to laugh at your jokes if you ain't funny. I don't have to agree with you when I have my own opinion.'

'So my aunt and cousin, they tells me, "the VA says you'll never be able to handle your money." And that kind of upset me cause, see cause I've been with the VA for 34 years and I know what they will do and what they will not do. And see they don't. See they were handling my money and then... and then so I got a resentment and I went out and I got one of my checks, I get social security to me and my aunt was upset about that cause she was handling both checks.'

'What we do at Friends for Recovery, we self advocate for ourselves ... we stand up for our rights and we speak to the public and we let them know that . . that we're not gonna sit down and take what's been fed to us about being schizophrenia'

'You know, don't let mental illness penalize you. Just do whatever you need to do.'

'I don't want people to think that I'm abnormal more than anybody else is.'

\section{Writing and rewriting}

The person's unique experience of the phenomenon shows itself as ...

It was important for the individual to reestablish his rights, how he is regarded by others, and his relationship to them.

\section{Essential theme}

The importance of being accepted as he is

Presented in the overarching theme 'They assert their autonomy' 
Table 6. Example of the revealing of one essential theme (theme 4) from narratives

Holistic Reading Approach

The illness means that a reorientation with new levels of insight has occurred. This

change is experienced as transformative

Theme

Resilience

Selective Reading Approach

[Because of his diagnosis of schizophrenia he says] 'I just felt special cause, you know, having a vivid imagination. You know, it all starts off with that $12^{\text {th }}$ grade education, and right now I feel like I could be anything I want to be because I've done that.'

'I think I'm gonna be a better person because of the illness. What I know I wouldn't have known then. I probably would not have been more receptive to the people to have this illness or more understanding. I get along with my peers just fine.'

'And. . like I told you, I got sober from drugs and alcohol, that's when I started to see that my disability as it is in my life, you know. I guess they say living life on life's terms. I'm doing that, living life without... without alcohol and drugs, without craziness, you know. I don't do things crazy other than I might talk a little crazy.'

'You know sometimes I be thinking about these therapists and these psychologists and psychiatric workers, you have to ask yourself .... And I'll be saying, ah... yeah I guess you got a lot of schoolin, you went to school and spent a lot of time in that field, but you are fortunate, cause I don't feel that you know more, I'm 52 and you not no smarter and no more intelligent than I am. That's the way I feel. I know you may be in that position and also I noticed that they treat people the same, you can't treat everybody the same, everybody is not gonna have the same issues.'

Writing and rewriting

The person's unique experience of the phenomenon shows as. . The life situation means meeting approaching life with special abilities that have been acquired because of the illness.

Essential theme

Resilience

Presented in the overarching theme " They experience reality differently' 
Theme 1: They know that they are mentally ill (recognize that they have symptoms)

Sub themes; Dragged through time, symptoms do remainThe participants are aware of the signs and symptoms of schizophrenia as related to the specifics findings in their own experiences with illness. Sometimes, the family is the first to recognize that the individual appears ill. Tyrone reports pushing his mother, and that she subsequently had him admitted to an inpatient psychiatric unit in the local Veterans' Affairs medical center. He states:

I guess that's not too keen, shoving your mother, 'cause they put me on medicines that, you know, the kind of medicines they use that ... and I was up there 30 days and I came out and it wasn't long after, I was back in the hospital again you know, for that. I don't know what I had that next time but I guess (I) was incoherent or something. But she put me back in.

Tyrone acknowledges that he was incoherent and needed medication that he states continues to be beneficial for him. He speaks of never wanting to return to the hospital, even though his last inpatient stay was more than 30 years ago.

Paul maintains that he was hearing voices, experiencing forgetfulness and was unable to stay focused. Paul believes that his illness was related to the stress of attempting to work two jobs while attending high school. He reports that he is not hearing voices presently.

David speaks of losing his temper and destroying furniture at home as precipitating his first admission and subsequent diagnosis. David stated that he was 'paranoid' and 'I would,... every time my mother would go across a bridge or something, I would think about turning the wheel and just going into the ... going in to the water, but I never did it. I guess . . thank God, I never did it or I wouldn’t be here today." 
Anthony reading from a paper that he prepared for the interview, "I see things that others possible don't see."

Some participants describe the initial signs of their condition as though they had 'caught the illness', just as one catches a cold. This is how Anthony recalls the first time he observed his symptoms. He was on an airplane traveling from California to New York "and all of a sudden I just... when I got to New York, I just got the illness."

Darius reports using "different substances and doing a lot of drinking and that he was given the diagnosis". Prior to the formal tape interview, he contrasted what his life was like at the time as compared to now. "Then there was chaos and confusion and now there is peace and clarity about who he is," according to Darius.

Even in the absence of articulating an understanding of the cause of their schizophrenic conditions, all of the participants could clearly articulate both positive and negative signs and symptoms that they displayed, which are consistent with their diagnosis. In addition they were able to discuss how these symptoms may have contributed to difficulties for themselves and others.

\section{Dragged along by time}

The respondents expressed no definitive plans for accomplishing their daily activities other than those behaviors that serve as basic physiological maintenance functions. There was little other preplanning of their day as reported by how they spent their days. Most adults when asked about how they planned to use their time, do not usually report activities of daily living as events requiring special note, but assume such things as givens. The amotivational behavioral responses reported seem to go beyond 
mere concrete thinking usually associate with schizophrenia, but rather appeared related to a passivity usually observed in persons who believe that they have unlimited time, such as adolescents. In this manner the participants allow time to manage them instead of structuring their use of time. This attitude is opposite from others with chronic illnesses, who may have a sense that time is extremely limited or denote much of their time in the management of their illness (Strauss \& Glaser, 1975; Thome, et al., 2004). The typical approach to their daily activities consists of 'seeing what the day would bring.' Some of the comments made in response to the inquiry as to what an average day was like were as follows:

Anthony: Oh, I go to the store sometimes and I get groceries and . . I . . well, I used to work and now that I have a little job, I go and put gas in my car once in awhile and other than that, not much. Once in a while I go the gym but that's only a little few ... like that's ... on occasion, I don't go that much to the gym.

Darius: A typical day would be, for me, you know I wake up and might read some scripture out the Bible and I eat my breakfast. I plan my day, I come here or if I have a doctor's appointment I'll go see a doctor or whatever I have to do, I do that, take care of that. And ... A typical day for me is pretty average. Yeah, I would say a typical day for me would be pretty average.

Tyrone: I tell you I'm trying to find inspiration to get up the morning. You know

I got all this time on my hands.

David: Well, a typical when I was feeling good, I was a ... I had a lot of positive goals I want to accomplish, I don't see this illness holding me back, matter of fact I don't see myself with having the illness at all. But on a bad day it's like I don't want to be around people.

Paul: A typical day, just a regular day? Ok. If it's a good day, get out, go to a day time program. Participate in that, go home, watch TV, and bathe. I eat breakfast, lunch and dinner. Going out, you know, going like every other Wednesday, going to get my lab work done, going out in the community, doing stuff in the community. 
Interestingly, no one reported any perceptions of time distortions. Participants did not sense a slowing or speeding up of time, in the face of unstructured days. Symptoms do remain.

Many of the respondents report that they still experience on-going symptoms associated with schizophrenia. However, these symptoms have become less intense and intrusive. In addition, the participants do not necessarily act on the symptoms. For example, although Anthony believes that others can read his thoughts, he still engages in activities outside of his apartment. Related to this factor, the participants appear to have insight into behaviors that precipitate difficulties for themselves and others in their environment. They are especially cognizant of those behaviors that could result in hospitalization on an inpatient psychiatric unit. One measure of success that each individual reports with pride is the length of time since his last hospitalization.

\section{Summary}

The respondents demonstrate insight as reflected in their narratives that delusions and hallucinations are not shared by others, but rather are something that is part of their own experiences. Although, some of the men report that they continue to have the positive symptoms of schizophrenia they insist that experience are both less intense and less intrusive. Therefore the participants no longer feel compelled to act on this jarring symptomatology. They appear to recognize the behaviors that they are required to exhibit or refrain from performing in order to function in the larger society and have mastered these responses. 
A typical day consists of a wait to see what the day brings attitude associated with vague, somewhat amorphous plans. Frequently, time is structured around therapeutic appointments and peer support group meetings, such as, Alcoholics Anonymous and NAMI. Race and gender were not reported as additional challenges for these respondents. Theme 2: They make a special effort to test reality

Anthony, who reported that his thoughts could be read by others, asked the researcher during the interview if she could "read his mind". He then indicated that he had asked his psychiatrist, counselor and case manager if they could read his mind. He reported that each had said 'no', thus giving the researcher the impression that Anthony uses this inquiry to determine if, in fact these caregivers were engaged in what he believed were actual invasions of his mental 'self'.

Tyrone narrated a story about a woman whom he was dating that he believed was seeing other men, so he posed a series of questions like an attorney would ask a witness in a trial. Here are his words, "this girlfriend I had, I wanted her to say the wrong thing and I thought of a word that she would say. She was saying the wrong things. And I questioned her and she said them exact words and she wanted to marry me, that's why I said it. I just wanted to know if she was true to me, but after that I didn't think she was true to me so I didn't marry her." Tyrone went on to say that the reason he did not marry this woman was because he had verified in his mind that she had lied and therefore was not trustworthy. He stated further "Why she wanted to marry me, if she'll tell me a lie. You know, shouldn't be no lies in a relationship." 
Darius outlined his testing thusly, “in my family and other people’s families too . . . is that is they have certain issues, or might have certain mental health issues also, but they don't want to be honest to acknowledge it. You know, because . . . It's like when you know yourself; certain symptoms that you may be dealing with, you can see it in other people too.”

Anthony asked "I mean, what do you think of everything that I've said to you?" The participant asked this question at the conclusion of the interview to determine the researcher's evaluation of the content of his conversation. When the interviewer responded that she appreciated his honesty and his willingness to participate in the study, Anthony nodded affirmatively and smiled. This was the only time he smiled during the interview.

\section{Summary}

Closely aligned to the insight that the participants relate to their symptoms are their efforts to determine what is 'real' or 'true' in their relationships with others. They frequently engage in testing and questioning the words and behavior of others for validation with respect to their own observations and beliefs. They use these measures to determine where they stand in relation to others. The other person may not realize the nature of the inquisition until confronted by the "evidence" collected and analyzed by the respondent.

\section{Theme 3: They assert their autonomy}

Sub themes: Accept me as I am, what you see is what you get, Close Community (CC) versus Outside Community (OC) 
The participants are living independently in the community and strive to maintain that degree of self-determination. They acknowledge a sense of self and discuss a level of comfort with who they are. In response to seeking their perceptions of how they are viewed since being diagnosed with schizophrenia the following sub themes emerged within the overarching focus on declaring and asserting their autonomy.

\section{Accept me as I am}

The participants describe their idealized selves using positive adjectives. There is a pervasive sense of satisfaction with their present lives that permeates all the narratives. The manner in which they would like to be viewed and saw themselves stimulated the following self assessments:

Darius:

I would like for people to say, hey, you know, I was a nice person. I was an easy going person, I was a fair person. I was good people and at the end of the night I would say, hey I would like for them to see me as an honest person, straight forward person. I'm gonna say how I feel, I'm gonna tell you how it is. I'm not going to sugar coat nothing. I'm not going to put on no airs. You accept me for who I am, or I really don't care.

Anthony:

Well that I'm a nice person and that ... I'm polite and I respect everyone. And... I don't want people to think that I'm abnormal more than anybody else is. Because sometimes they'll think that whenever I enter a place or enter somewhere then they'll look at me and think that I... that they know something about me or they'll look at me weird... that they'll act weird in front of me.

David:

what we do at Friends for Recovery, we self advocate for ourselves and in between, we stand up for our rights and we speak to the public and we let them know that ... that we're not gonna sit down and take what's been fed to us about being schizophrenia or being bi polar or having depression... that we feel we can function in this world ... That we have a right to things just like they have a right 
to do things and ... a and we're not crazy like they call us sometimes. Basically we can function just the same as any human being if they give us a chance.

Paul: I am the typical nice person. I'm nice, humble, honest, motivated, caring, helpful, understanding and compassionate.

Paul further states that "people need to stay motivated with what they're doing, not to say oh this person has a, this illness and he can't function this way, you know, just to continue to motivate people and their mental health . . you know, don't let their . . . you know, mental illness penalize you. Just do whatever you need to do." What you see is what you get

There is a desire for authenticity and validation of how they see themselves as an important component of their sense of self. A determination to maintain the boundaries and integrity of their personhood fueled the dialog contained here.

Darius:

Yeah, it doesn't bother me, it doesn't bother me. If that's the only thing that I had to worry about was people who talk about me or people who think this way or that way about me, then I would really be messed up on the head. I don't care, you know ... I'm sure if you were walking in my own shoes you would feel the same way they are not supporting you, they don't pay your bills, you don't have to answer to them. I'm not here to put on no airs, I'm not here to please nobody, I'm nobody's yes man, and I don't have to laugh at your jokes if you ain't funny. I don't have to agree with you when I have my own opinion.

Tyrone: my illness don't bother me, And that's what I do, live through my illness.

\section{Close Community [CC] versus Outside Community [OC]}

The participants distinguished between those who were accepting and supportive, Close Community, $[\mathrm{CC}]$ and those that were stigmatizing and rejecting, Outside Community [OC]. Family members, friends and their trusted 
therapists were considered CC. Although the participants did not use these terms themselves, these designations emerged as a result of the interpretive process of the inquiry. The hermeneutic team saw the terms as a good fit with the data based in the narratives and the researcher's reflexive notes.

David spoke of his mother in this manner:

Then I started to listen to the doctor and I started listening to my mother more. She started getting more involved and all with the ... what the doctor was doing and how he was treating us. So, that kind of helped me out a lot. Which I appreciate, I guess I can't tell her enough that I appreciate it. That the love she showed me in there and when she talked to the doctor and stuff like that. They say it was like one day I just woke up, that's what the nurse and my doctor said and my mother always said it's as though like, one day while was in Central State for like 2 years and a half and, it's like one day it's like all of a sudden I just woke up. [CC]

Paul communicated his opinion like this:

They, they (friends, family, case manager), you know, helped me through it. You know made sure I took the proper medications and . . . stuff like that. Make sure I could still do what I was doing before I got sick, you know, working and you know, doing stuff in the community. But at the end of the day they ... they accepted it and you know, they didn't criticize me; they just tried to help me; to encourage me to do it. You know, made sure that I could still do what I was normally doing before, but now everybody's fine with it. They understand and don't criticize or nothing like that so. [CC]

David made the following statement about the Outside Community:

I realized that I had to get back into society and that was one of my goals is to be accepted again and show them that because I got a illness that doesn't mean I'm not a human being. That doesn't mean I'm not, that doesn't mean that I'm a bad person. I can focus, I can work, and I can do just as much as they can do, if not more if I put my mind to it. So the general public has been acceptive of me but there's also are some stigma, just saying that because you have . . . your mad . . . Because you have schizophrenia that that, you're prone to violence outbreaks and that you can't function or either that you can't do so much, can't do but so much in this world. And that you ah ... most of the time you end up homeless on the streets or in jail and all that. I just want to prove them wrong. [OC] 
Darius responded emphatically:

I have gotten to the point that, first of all number 1, I don't care, and number $2 \ldots$ I don't have to get along with you; I don't have to kiss your butt. And number 3 is I'm my own person. And people are going to talk about you regardless. [OC]

All the participants have had inpatient psychiatric hospitalizations previously and are currently enrolled in outpatient therapy of varying levels of intensity including medication management. None of the men reports difficulty accessing adequate care.

\section{Summary}

As part of the process of ensuring self-determination and asserting their autonomy, the respondents actively divided others into two groups; supporters and detractors. Supporters accepted their individuality and did not require the men to present false personae. This group [Close Community] composed of family members, friends and sometimes therapists were spoken of with respect and appreciation. However, harsh criticism was directed toward those considered to be in the Outside Community. This response seems to be related to the belief that the OC possessed a negative assessment of the participants and offered no goodwill towards individuals with mental illnesses to include the participants. Therefore, the respondents stated, emphatically, that they had no intentions of currying the favor or seeking the approval of the OC. Rather, some of the participants looked to demonstrate, with their own progress, that the OC's pessimistic evaluations are inaccurate and stigmatizing

Theme 4: They experience reality differently, which they see as unique

Sub Theme, Resilience 
The participants often referred to themselves as having special or unique knowledge, understanding and in connection with their schizophrenia. These include the expectation that they can perform tasks that require extensive education and training on the part of others. They also indicated that having schizophrenia provides them with special favor and creative abilities. The unique knowledge appeared to be different than the pathologically based grandiosity which is sometimes seen in schizophrenia in that it seemed to facilitate the participants adapting to society. In this way, the 'special knowledge' had a negating effect on the alienation and separation of the individual which also is observed often in persons diagnosed with this disorder.

Tyrone:

I just felt special cause, you know, having a vivid imagination, it takes up the time of the day for you. You know like, if I think awhile.... You know cause they say you only need a $12^{\text {th }}$ grade education to do and you could be anything in the world you want to be. You know, it all starts off with that $12^{\text {th }}$ grade education, and right now I feel like I could be anything I want to be because I've done that.

David: Right now, that I'm ok. I'm doing fine. I think I'm gonna be a better person because of the illness. If I didn't have these feelings; I probably would not have been more receptive to the people who have this illness.

Darius stated the following to demonstrate his special observational skills:

I can see and feel things from certain people and it's not to the point that I would say he or she is crazy, I understand them. And that's very important. And maybe he or she might say this or they may do that, but I'll allow that and let that go because I understand the person and I understand myself. So that's what I would to say the experience with that you know, with me. You know sometimes I be thinking about these therapists and these psychologists and psychiatric workers, you have to ask yourself .... And I'll be saying, ah... yeah I guess you got a lot of schoolin, you went to school and spent a lot of time in that field, but you are fortunate, cause I don't feel that you know more, I'm 52 and you not no smarter and no more intelligent than I am. That's the way I feel. I know you may be in 
that position and also I noticed that they treat people the same, you can't treat everybody the same, everybody is not gonna have the same issues.

David described the following perception to indicate his unique status:

when I was at Central State and like I had an angel at the back door who was watching over me and was telling me what to do and everything was going to be alright and once I really came around to understanding why I was there in the first place and what they was doing, then the Angel told me his name and they sent him back into heaven.

\section{Resilience}

The participants indicated in their narratives that their experience of living with the diagnosis of schizophrenia was transformative. That, by coming to terms with the diagnosis, they had achieve an intimate knowledge of themselves. They use this knowledge for self improvement and sometimes to advocate for others.

Tyrone: I guess as they say about living life on life's terms. I'm doing that, living life without ... without alcohol and drugs, without craziness, you now. I don't do things crazy other than I might talk a little crazy.

Darius:

Of course you got to deal with yourself. Who you look in the mirror to? Yourself! You can't shuck nobody. You can't pull the wool over nobody. And that would be, you know, my suggestion. People are different; I mean people are not the same most definitely. And I've learned that. I feel I've learned . . . and I feel that you know a lot of people who have made it in life to a point that you know they feel their mental issues are something they want to hide undercover. You can be the President to the United States and have issues and problems. You can be the mayor; you know to have substance abuse problem or whatever. Cause it's always something. If it's not one thing, its other things.

It appeared that Darius spoke in this manner as a way to indicate that he had earned the right to be taken seriously as contributor to society. It further appears that he 
was saying that each of us, regardless of social status, has a responsibility to face and

honestly address any personal need for improvement.

Tyrone:

For me, you know I just keep on trudging along. You know something the bible says a lot of people don't see, but I see? It says keep your head in the clouds but your feet firmly on the ground. But I try to keep my head in the clouds with my feet firmly on the ground. David:

I started advocating for other patients. I started saying like, well I think that is what this was wrong with this person even though I wasn't no doctor and couldn't ... like you know, if they got or really admire it but I just like, I just put my two cent in there I guess you could say and like when I think this is wrong with him cause I had the same symptoms, so maybe we can ... Maybe you all can all look into it together.

David says about having the diagnosis of schizophrenia:

There is a lot you learn about; how other people perceive you; how well you are respected in the community; how well you see yourself. This is something that can control your life or this is something you can deal with and get over with and move on past it and be a better person because of it. I've learned to be a better person because of it.

\section{Summary}

The men in this study report a sense that their illness provides them with special insights and enhanced abilities. They claim to use these powers to improve their own well-being and that of others. They believe that they possess distinguishing characteristics that make them unique. 


\section{Chapter 5}

\section{Conclusions, Discussion, Implications, and Limitations}

\section{Introduction}

The purpose of this chapter is to (1) present and discuss the conclusions of the study; (2) outline the implications of the study; (3) present limitations of the study and (4) delineate areas for future research. This study was undertaken within the hermeneutic phenomenological framework to understand the experiences of African American males with schizophrenia. The study utilized a method outlined by van Manen (1990, 1997). Therefore the conclusions reached are part of a motif that connects the themes articulated by the participants.

\section{Conclusions}

The following conclusions listed below are related to the experiences of African American males diagnosed with schizophrenia that emerged from the findings presented in Chapter Four. These findings will be discussed in relation to each of the themes previously identified.

1. Participants did not acknowledge that being African American or male posed an additional challenge to their lives. A consideration here is that these men may navigate in a subculture that has limited intersection with the dominant culture such as exists in the work place where competition and demands for productivity prevail. Therefore, they may be insulated 
from the negative impact of stigmatizations of race, gender and chronic severe mental illness.

2. Four of the five participants attended peer support activities on a regular basis (at least monthly).

3. Two participants were peer counselors in peer support organizations.

4. Four of the men reported positive family support; the fifth indicated engagement with his family, but did not characterize it as positive or negative.

5. Participants describe themselves in a positive light, with some viewing themselves as having unique and special abilities.

6. Respondents did not talk of loss, struggle and suffering in their narratives, each appeared to embrace the diagnosis of schizophrenia as a part of who they are, but not the entirety of their persona. This finding could well be related to the fact that these participants are highly functioning individuals, self selected to be part of the study.

\section{Discussion}

Theme 1- They know that they are mentally ill

The participants clearly articulated the symptoms of schizophrenia and were able to describe the impact that these symptoms had on their lives. They were particularly focused on those behaviors that resulted in hospitalizations and avoided those behaviors to the best of their ability. Lincoln et al (2007), in their review of longitudinal studies that 
addressed long-term consequences of poor insight for individuals with schizophrenia, found that the majority of the studies speak to a clear relationship of poor insight with limited treatment adherence. So in this respect, the high level of insight expressed by the participants in this study corresponds with their high-levels of treatment adherence. What is of interest, however, is that several of the participants still reported some symptom of schizophrenia, despite being treatment adherent. Anthony continues to believe that people can read his mind. Tyrone speaks of being able to control the behavior of others with his thoughts, while David reports that he sometimes has difficulty distinguishing what is real from that which is false.

Usher (2001) in her phenomenological study of medication adherence in persons diagnosed with schizophrenia discussed the difficulties that subjects reported related to side effects. The respondents referred to their body "losing its transparency" as a result of side effects that caused them to stand out and be different. In the current study, the men did not report this type of bodily being-in-the-world. In point of fact, Anthony reported that people in the community were not aware of him as different although he is medication adherent. Paul reported a similar experience, where a woman in his peer support group stated that "he did not talk like he had schizophrenia," but rather assumed that he was attending the group as a family member as was she. One of the differences that may account for the lack of expressed concerns about medication side effects in these respondents may be related to the fact that all of the participants are taking newer atypical 
psychotropic medications rather than the older, more traditional anti-psychotic agents with more stigmatic side-effects such as tardive dyskinesia.

As to the participants being "dragged through time," only Tyrone discussed this as being a cause of concern for him. Although the literature on recovery in schizophrenia is replete with recommendation for meaningful work for individual to be considered “ fully recovered” (Liberman et al.,2002;Liberman \& Kopelowicz, 2005; Torgalsboen \&Rund, 2010; Harrow et al., 2005; Lysaker, Roe, \& Buck, 2010), these studies address objective measures, whereas here we are taking the "inside out" perspective. The participants have structured their own processes for managing their days to their own satisfaction. In this way their philosophy on use of time is more in concert with that of Deegan (2005) that centers on personal choice in self-management of one's own life for persons with psychiatric illnesses.

An interesting finding is that participants did not report that being African American and male added a burden to their diagnosis of schizophrenia. This is one of the assumptions with which the researcher entered into the study, a factor that has been previously suggested in the literature. For example, a qualitative study by Spaniol et al. (2002) reported that African American participants experienced a double stigma of race and mental illness. What is intriguing is that the narratives that the authors used to support this claim were both made by African American females. Also, the participants were not exclusively diagnosed with schizophrenia and all three of the African American 
males in the study had substance abuse disorders. This co-morbidity may be significant in contributing to the individual's history of homeliness and economic challenges.

\section{Theme 2- They make a special effort to test reality}

David stated, “[be]cause I can’t distinguish the real from reality, I mean the fake from reality sometimes, sometimes it's kind of hard to distinguish the both of them, which is real and which is fake." This seems to be an experience common to the participants, with most giving examples in their narratives of times and ways that they seek clarification and affirmation from others in the environment. Esso Leete, who identifies herself as having schizophrenia, discusses the phenomena as follows, "it has been invaluable to have someone I trust (often my husband) with whom I can 'test reality.' I let him know my perceptions and he gives me feedback. I am then able to consider the possibility that my perceptions may not be accurate, and I modify my response accordingly, if I wish.”

It appears that the men in this study participate in the same activities to varying degrees. There appears to be hyper-vigilance and sensitivity on the part of the participants to seek to employ the usual or conventional ways of thinking of others in order to prevent what may be a delusional assessment from coloring outside information. Two of the participants mentioned to the researcher, prior to their formal interviews, that they sometimes discuss ideas and thoughts with members of their peer support group to help them clarify their thinking.

Theme 3 -They assert their autonomy 
The respondents all reported positive self assessments. It is not clear if this has always been the case for each of the men, but the narratives reflect where they are now, in terms of self image. It would have been interesting to know if this is a point with which they had struggled and worked to obtain a positive self-image, or was this the natural inclination of these particular five individuals. Whatever the contributing factors, the logical outcome of this positive self regard is the expectation that one be accepted "as is". Related to this idea, is the lack of need to hide who they are, because the "what you see, is what you get" perspective implies that they are all right just as they are. The participants describe themselves as nice, honest, humble and compassionate. What fault can be found with these traits? There is no necessity to change.

A contributing factor may well be the support system that the participants all report having in the form of family, friends and/or therapists. The researcher refers to these people as Close Community $(C C)$. The CCs are described as accepting, loyal and concerned by the participants. CCs have earned the trust of the participants and their assessments and opinions seem to matter to each of the men. There appears to be a distinction made between the CCs and those who appear outside the respondents' boundary of trust. This latter group is referred to as the Outside Community $(O C)$ by the investigator. Conversely the $\mathrm{OC}$ is viewed as consisting of individuals who are rejecting and hold negative views about the mentally ill. Darius and David reported the strongest negative evaluations of the impact that the OC should be allowed to have on their lives. 
According to these participants, OCs are to be disregarded and their negative feedback ignored, as they bring nothing of value to the table.

Shea (2010) used grounded theory to conduct a study for the purpose of describing the process of self-identity reconstruction in people with schizophrenia. The author described activities that seem relevant to this theme, finding a social fit and coming back normal. As part of the process of finding a social fit, the individuals looked for people who accepted them and places where they felt comfortable. In this study, the participants clearly identified people, whom they believed accepted them. They also indicated places that they went where they felt comfortable. For example with Darius, it was the gym; David, the library; and, Tyrone, his neighbor's house. In terms of the coming back normal, the subjects in Shea's inquiry identified resources within and outside of themselves that allowed them to exercise control over their own lives. This certainly seems to be the case of the African American men in this study. The respondents emphatically deny that being an African American male represents an additional challenge.

Darius talked about this as a concept, but not as individual issue for himself . .

We all gonna have that. I don't care who you are, I don't care how high you get up in there, at the end of the night, certain kind of ethnic group wants to get around their own kind. You know, we always gonna be talked about ... we always gonna be put down and for the simple reason, for the simple reason I feel cause we are a threat to them. We'll always be a threat so that's how I look at that.

David stated: 
No, not really. I see no difference than if it was a black person, white person with schizophrenia, or a Mexican with schizophrenia, but ... I think they say we are more prone to violence. We're more likely to get the disease than other races, cause of our genetic makeup.

Anthony did not address any concern about the relationship of his schizophrenia and ethnicity and gender.

When ask the question Tyrone stated, "Acknowledging it from others, you know, is like.... You know cause I could deal with loneliness cause I was an only child and stuff like that. He then talked about how being alone did not bother him.

Paul responded, "Not ... [sic] not really"

Theme 4 -They experience reality differently [in which they see themselves as unique]

Geanellos (2005) endeavored to understand how people experience schizophrenia by reviewing the stories of 19 people diagnosed with the disorder using hermeneutic interpretation. These stories appeared as first person accounts in the journal Schizophrenia Bulletin. One of the themes that the author identified was called, Reconstruction: Renewed resilience and the recast self. The researcher stated that the individuals reconnected with their lives through a range of activities and relationships and drew on a buoyed self to relate to aspects of that individual's life. After completing the review, the author concluded that adversity provides opportunity to adapt to life's challenges and enhance resilience. This is what it appears that the participants were reporting. Tyrone spoke of living life on life's terms. Darius described everyone having "issues and problems" and indicated that he believed that he possessed special insight into the motives of other to facilitate his problem solving. This belief that one has special 
powers and abilities seems to provide the respondents with psychological protection or armor that assists them with organizing and coping with their world.

\section{Implications for Future Practice, Research, and Policy Implications for Practice}

The implications for treatment are grounded in recognition of the client's ability to determine who is supportive of his autonomy and who is not. In order to participate in shared decision making with the client, the nurse must be viewed as a Close Community person as opposed an inhabitant of the Outside Community. The individuals view themselves as unique and special and therefore expect to be perceived that way by the staff. Otherwise, there will be resistance by the client to partnering with the nurses in the healing process. It serves no useful purpose therefore, for the nursing staff to practice 'one ups man ship' with the client, because based on these findings; the clients see themselves having the authority, power, tools, knowledge and responsibility to resist what is seen as threats to their autonomy and sense of self-worth. The staff member is truly a "visitor" in the client's world. As such, the individual has the power to invite the staff in or exclude them. In terms of symptom management, the client may not be free of hallucinations and delusions, but nevertheless may be at his optimum state of wellness and able to live productively in society.

The power of peer support groups has been recognized in substance abuse but much less so, in the treatment of schizophrenia. The respondents clearly indicated that peer support was pivotal to their well-being. Darius and David are actively engaged in 
speaking to others with mental illnesses serving as peer counselors. Darius reports that he makes presentations to inpatients during which he encourages them to consider joining his peer support group after they are discharged. Darius reports that he tells his audience that the organization that he is a part of has been beneficial to him, therefore they too might find it useful. David proudly discussed that his peer support group is putting together a book, which will include poems, artwork and short stories from the members of his group. He clearly distinguished the beneficial impact of this advocacy community on his dealing with his condition.

\section{Implications for Research}

It would be interesting to conduct a study using a larger cohort of individuals diagnosed with schizophrenia to determine if the same or similar themes emerge, and to identify the variables which account for this state of recovery. To this end, I envision conducting a study on patients who have not made a recovery adjustment, using the same research protocol as employed in my study. These non-recoverers can be identified by frequent re-hospitalizations, intrusive, troublesome symptoms and impaired reality testing, critical features diametrically opposed to the experience of the recoverers in this study. Not infrequently, non-recoverers are arrested for misdemeanors and are incarcerated, a situation which increases their social isolation, criminalizes their illness, and impedes any attempt to foster their subjectivity and autonomy. Medication adherence is a variable identified by other investigators; however, how the non-recoverers 
experience medication-taking would be critical in designing medication adherence monitoring interventions.

\section{Implications for Policy}

It is essential that effective outpatient care be provided in order for stability [treatment adherence] to be maintained. Previous research has identified many of the barriers to access, but barriers cannot be removed without a more penetrating understanding of how the non-recoverers experience the impediments. One significant finding of this study is that the recoverers were actively engaged in peer support groups, a cost-effective intervention. An official inclusion of philosophically and therapeutically sound peer group support is recommended using agencies that provide outpatient services to individuals with mental illnesses. These alliances need to be formalized in providing care rather than being maintained on an adhoc basis.

\section{Limitations of the Study}

The study was restricted to three contiguous communities (Richmond, Williamsburg, and Hampton, Virginia). While there were common experiences reported by all the individuals in this inquiry, perhaps replication of the study in other geographic areas would produced some variation in outcomes. All the participants were receiving disability payments adequate to meet their basic needs, therefore issues related to financial concerns, such as homelessness were not expressed. This may have impacted the emphases noted in their activities of daily living as reflected in the study's findings. 
All the participants are treatment adherent. The impact of nonadherence to treatment with respect to study outcomes could also be examined.

\section{Conclusion}

This chapter has presented and discussed conclusions and themes of the study, outlined the implications noted, presented perceived limitations and delineated areas for future research. Areas of future investigation were outlined for research, education and practice, and public policy. Limitations of the scholarly inquiry were also presented. The overall investigative research has provided distinct insight into what it is like for an African American male living with the diagnosis of schizophrenia. The realization that these men have transcended their diagnosis of schizophrenia rather than being crushed by their condition was evident in their stories 


\section{References}

American Psychiatric Association (2002). Diagnostic and Statistical Manual of mental Disorders DSM-IV-TR. Washington DC: American Psychiatric Association.

Agency for Healthcare Research and Quality. (n.d.). The Schizophrenia Patient Outcomes Research Team (PORT) treatment recommendations: at issue translating research into practice. Retrieved November 5, 2010 from http://www.ahrq.gov/clinic/schzrec.htm

Anglin, D. M., Link, B. G., \& Phelan, J. C. (2006). Racial differences in stigmatizing attitudes toward people with mental illness. Psychiatric Services, 57(6), 857-862.

Barnes, A. (2008). Race and hospital diagnosis of schizophrenia and moods disorders. Social Work, 53(1), 77-83.

Beebe, L. H. (2010). What community living problems do persons with schizophrenia report during periods of stability? Perspectives in Psychiatric Care, 46(1), 48-56.

Bernard Flynn. (14). Maurice Merleau-Ponty. Retrieved from http://plato.stanford.edu/entries/merleau-ponty/

Berrios, G. E., Luque, R., \& Villagran, J. M. (2003). Schizophrenia: A Conceptual History. International Journal of Psychology and Psychological Therapy, 3(2), 111-140.

Borowsky, S. J., et al. (2000). Who is at risk of nondetection of mental health problems in primary care? Journal of General Internal Medicine, 15(6), 381-388. 
Carpenter-Song, E., Whitley, R., Lawson, W., Quimby, E., \& Drake, R. E. (2009).

Reducing Disparities in mental health care: Suggestions from the DartmouthHoward collaboration. Community Mental Health J, 07 August 2009, doi: $10.1007 / \mathrm{s} 10597-009-9233-4$

Cheatham, C. T., Barksdale, D. J., \& Rogers, S. G. (2008). Barriers to health care and health-seeking behaviors faced by Black men. Journal of the American Academy of Nurse Practitioners, 20(11), 555-562.

Colaizzi, J. (2004). The unfortunates committed to our care: The history of Eastern State Hospital, Williamsburg, Virginia from 1865. Williamsburg, Virginia:

Coleman, P. (1992). Breaking the chains: The crusade of Dorothea Lynde Dix. New York: ASJA Press.

Compton, M. T., Esterberg, M. L., \& Broussard, B. (2008). Causes of schizophrenia reported by urban African American lay community members. Comprehensive Psychiatry, 49, 87-93.

Corrigan, P. W. (2007). How clinical diagnosis might exacerbate the stigma of mental illness. Social Work, 15(1), 31-39.

Corrigan, P. W., et al. (2010). Self-stigma and coming out about one's mental illness. Journal of Community Psychology, 38(3), 259-275.

Creswell, J. W. (2007). Qualitative inquiry \& research design: Choosing among five approaches. Thousand Oaks, California: SAGE Publications. 
Crotty, M. (1998). The foundations of social science research: Meaning and perspective in the research process. Thousand Oaks, California: SAGE Publications.

Davidson, L. (2003). Living outside mental illness: Qualitative studies of recovery in schizophrenia. New York: New York University Press.

Deegan, P.E. (2005). The importance of personal medicine: A qualitative study of resilience in people with psychiatric disabilities. Scandinavian Journal of Public Health, 33(Suppl 66), 29-35.

Dowling, M. (2005). From Husserl to van Manen. A review of different phenomenological approaches. International Journal of Nursing Studies, 44, 131142.

dosReis, S., Zito, J. M., Buchanan, R. W., \& Lehman, A. F. (2002). Antipsychotic dosing and concurrent psychotropic treatments for Medicaid-Insured individuals with schizophrenia. Schizophrenia Bulletin, 28(4), 607-617.

Esterberg, M. L., \& Compton, M. T. (2006). Causes of schizophrenia reported by family members of urban African American hospitalized patients with schizophrenia. Comprehensive Psychiatry, 47, 221-226.

Esterberg, M. L., Compton, M. T., McGee, R., Shim, R., \& Hochman, K. (2008). Knowledge about schizophrenia and social distance towards individuals with schizophrenia: A survey among predominantly low-income, urban, African American community members. Journal of Psychiatric Practice, 14(2), 86-93. 
Fiscella, K., Franks, P., Doescher, M. P., \& Saver, B. G. (2002). Disparities in health care by race, ethnicity, and language among the insured: Findings from a national sample. Medical Care, 40(1), 52-59.

Fraguas, D., \& Breathnach, C. S. (2009). Problems with retrospective studies of the presence of schizophrenia. History of Psychiatry, 20(1), 61-71.

Gadamer, H. (1976). Philosophical hermeneutics. Los Angeles: University of California Press.

Gamble, C. J. (1945). State sterilization programs for the prophylactic control of mental disease and mental deficiency. American Journal of Psychiatry, 102(3), 289-293.

Geanellos, R. (2005). Adversity as opportunity: Living with schizophrenia and developing a resilient self. International Journal of Mental Health Nursing, 14, 715.

Geller, J. L. (1994). Issues in American Psychiatry reflected in remarks of APA presidents, 1844-1994. Hospital and Community Psychiatry, 45(10), 993-1003.

Greenwald, A. G., \& Banaji, M. R. (1995). Implicit social cognition: attitudes, selfesteem, and stereotypes. Psychological Review, 102(1), 4-27.

Hampton, M. Dc (2007). The role of treatment setting and high acuity in overdiagnosis of schizophrenia in African Americans. Archives of Psychiatric Nursing, 21(6), 327335. 
Harrow, M., Grossman, L. S., Jobe, T. H. (2005). Do patients with schizophrenia ever show periods of recovery? A 15-year multi-follow-up study. Schizophrenia Bulletin, 31(3), 723-734.

Heidegger, M. (1962). Being and Time. Oxford: Blackwell Publishers.

Heinrichs, R. W. (2003). Historical origins of schizophrenia: two early madmen and their illness. Journal of the History of the Behavioral Sciences, 39(4), 349-363.

Hines-Martin, V., Malone, M., Sanggil, K., \& Brown-Piper, A. (2003). Barriers to mental health care access in an African American population. Issues in Mental Health Nursing, 24, 237-256.

Hines-Martin, V. P. (2002). African American consumers: What should we know to meet their mental health needs? J Am Psychiatr Nurses Assoc, 8(6), 188-193.

House of Delegates, Virginia (2001). Expressing the General Assembly's regret for Virginia' experience with eugenics. House Joint Resolution, 607.

Ismail, Z., Rajji, T. K., \& Shulman, Kl (2010). Brief cognitive screening instruments: An update. International Journal of Geriatric Psychiatry, 25(2), 111-120.

Jarosinski, J. M. (2006). A life disrupted: Still lived (Doctoral dissertation, Virginia Commonwealth University, 2006). Dissertation Abstracts International, DAI-B 67/04, Oct 2006, 179.

Jarosinski, J. M. (2008). Exploring the experience of hallucinations from a perspective of self: Surviving and persevering. Journal of the American Psychiatric Nurses Association, 14(5), 353-362. 
Jenkins, J. H., \& Carpenter-Song, E. (2005). The paradigm of recovery from schizophrenia: Cultural conundrums of improvement. Culture, Medicine and Psychiatry, 10, 379-413.

Kelly, J. F., \& Greene, B. (2010). Diversity within African American, female therapist: Variability in clients' expectations and assumptions about the therapist. Psychotherapy Theory, Research, Practice, Training, 47(2), 186-197.

Kirk, S. A., \& Kutchins, H. (1992). The selling of DMS: the rhetoric of science in psychiatry. New York: Walter de Gruyter, Inc.

Koch, T. (1995). Interpretive approaches in nursing research: the influence of Husserl and Heidegger. Journal of Advanced Nursing, 21, 827-836.

Koch, T. (1996). Implementation of a hermeneutic inquiry in nursing: Philosophy rigour and representation. Journal of Advanced Nursing, 24, 174-184.

Leete, E. (1989). How I perceive and manage my illness. Schizophrenia Bulletin, 15(2), 197-200.

Lehman, A. F., Steinwachs, D. M., \& The Survey Co-Investigators Of The Port Project (1998). Patterns of usual care for schizophrenia: Initial results from the Schizophrenia Patient Outcome Research Team (PORT) client survey. Schizophrenia Bulletin, 24(1), 11-20.

Liberman, R. P., \& Kopelowicz, A. (2005). Recovery from schizophrenia: A concept in search of research. Psychiatric Services, 56, 735-742. 
Liberman, R. P., Kopelowicz, A., Ventura, J., \& Gutkind, D. (2002). Operational definition and factors related to recovery from schizophrenia. International Review of Psychiatry, 14, 256-272.

Lincoln, T. M., Lullman, E., \& Rief, W. (2007). Correlates and long-term consequences of poor insight in patients with schizophrenia. A systematic review. Schizophrenia Bulletin, 33(6), 1324-1342.

Lincoln, Y., \& Guba, E. (1985). Naturalistic Inquiry. London: Sage.

Luijpen, W. A., \& Koren, H. J. (1969). A first introduction to existential phenomenology. Pittsburgh: Duquesne University Press.

Lysaker, P. H., Roe, D., Buck, K. S. (2010). Recovery and wellness amidst schizophrenia: Definitions, evidence, and the implications for clinical practice. Journal of the American Psychiatric Nurses Association, 16(1), 36-42.

Madjar, I., \& Walton, J. A. (Eds.). (1999). Nursing and the experience of illness: Phenomenology in practice. New York: Routledge.

Metzl, J. M. (2009). The protest psychosis: How schizophrenia became a black disease. Boston, Massachusetts: Beacon Press.

Minsky, S., Vega, W., Miskimen, T., Gara, M., \& Escobar, J. (2003). Diagnostic patterns in Latino, African American, and European American Psychiatric patients. Arch Gen Psychiatry, 60, 637-644. 
Mishra, S. I., Lucksted, A., Gioia, D., Barnet, B., \& Baqet, C. R. (2009). Needs and preferences for receiving mental health information in an African American focus group sample. Community Ment Health J, 45, 117-126.

Munhall, P. L. (2007). Nursing Research: A quality perspective. Sudbury, Massachusetts: Jones and Bartlett Publishers.

Nair, A. K., et al. (2010). Clock drawing test ratings by dementia specialists: Interpreter reliability and diagnostic accuracy. The Journal of Neuropsychiatry and Clinical Neurosciences, 22(1), 85-92.

National Institute of Mental Health. (24). Retrieved from http://www.nimh.nih.gov

Neighbors, H. W., Trierweiler, S. J., Ford, B. C., \& Muroff, J. R. (2003). Racial differences in DSM diagnosis using a semi-structured instrument: the importance of clinical judgment in diagnosis of African Americans. Journal of Health and Social Behavior, 43, 237-256.

Newhill, C. E., \& Harris, D. (2007). African American consumers' perceptions of racial disparities in mental health services. Social Work in Public Health, 23, 107-124.

Peplau, H. E. (1952). Interpersonal relations in nursing: A conceptual frame of reference for psychodynamic nursing. New York: Putnam.

Peplau, H. E. (1987). Interpersonal constructs for nursing practice. Nursing Education Today, 7, 201-208. 
Ravenell, J. E., Johnson, W. Jar, \& Whitaker, E. E. (2006). African-American men's perception of health: A focus group study. Journal of the National Medical Association, 98(4), 544-550.

Sandelowski, M. (1986). The problem of rigor in qualitative research. Applied Nursing Science, 8(3), 27-37.

Shea, J. M. (2010). Coming back normal: the process of self-recovery in those with schizophrenia. Journal of the American Psychiatric Nurses Association, 16(1) 4351.

Snowden, L. R. (2003). Bias in mental health assessment and intervention. American Journal of Public Health, 93(2), 239-243.

Snowden, L. R., \& Cheung, F. K. (1990). Use of inpatient mental health services by members of ethnic minority groups. Is Psycho, 45, 347-355.

Spaniol, L., Wewiorski, N. J., Gagne, C., \& Anthony, W. A. (2002). The process of recovery from schizophrenia. International Review of Psychiatry, 14, 327-336.

Stanford Encyclopedia of Philosophy. (28). Retrieved November 5, 2010, from http://plato.stanford.edu/entries/phenomenology/

Stanford Encyclopedia of Philosophy, Flynn, B. (14).Maurice Merleau-Ponty . Retrieved November 9, 2010, from http://plato.stanford.edu/entries/merleau-ponty /

Strauss, A., \& Glaser, B. G. (1975). Chronic Illness and the Quality of Life. Saint Louis: The C. V. Mosby Company. 
Suite, D. H., La Bril, R., Primm, A., \& Harrison-Ross, P. (2007). Beyond misdiagnosis, misunderstanding and mistrust: Relevance of the historical perspective in the medical and mental health treatment of people of color. Journal of the National Medical Association, 99(8), 879-885.

Thome, B., Esbensen, B. A., Dykes, A-K., \& Hallberg, I. R. (2004). The meaning of having to live with cancer in old age. European Journal of Cancer Care, 13, 399408.

Thompson, J. W. (1994). Trends in the development of psychiatric services, 1844-1994. Hospital and Community Psychiatry, 45(10), 987-991.

Torgalsboen, A-K., Rund, B. R. (2010). Maintenance of recovery from schizophrenia at 20-year follow-up: what happened? Psychiatry, 73(1), 70-83.

Trierweiler, S. J., Muroff, J. R., Jackson, J. S., Neighbors, H. W., \& Munday, C. (2005). Clinical race, situational attributes, and diagnoses of mood versus schizophrenia disorders. Cultural Diversity and Ethnic Minority Psychology, 11(4), 351-364.

Trierweiler, S. J., Neighbors, H. W., Mundy, C., Thompson, E. E., Binion, V. J., \& Gomez, J. P. (2000). Clinician attributions associated with the diagnosis of schizophrenia in African American and non-African American patients. Journal of Counseling and Clinical Psychology, 68(1), 171-175.

U.S. Census Bureau (2010). U.S. Census Bureau population estimates by demographic characteristics. Washington, DC: U.S. Government Printing Office. Retrieved October 11, 2010, from http://www.census.gov 
Usher, K. (2001). Taking neuroleptic medications as the treatment for schizophrenia: A phenomenological study. Australian and New Zealand Journal of Mental Health Nursing, 10, 145-155.

van Manen, M. (1990). Researching lived experience: Human science for an action sensitive pedagogy. Albany, New York: State University of New York Press.

van Manen, M. (1997). Researching the lived experience: Human science for an action sensitive pedagogy (2nd ed., Rev.). Ontario: Althouse Press.

van Manen, M. (1998). Modalities of body in illness and health. Qualitative Health Research, 8(1), 7-24.

Varcarolis, E. M., \& Halter, M. J. (2010). Schizophrenia. In Foundations of psychiatric mental health nursing: A clinical approach (6th ed., pp. 307-343). St. Louise, MO: Saunders.

Walker, M. T. (2006). The social construction of mental illness and its implications for the recovery model. The International Journal of Psychosocial Rehabilitation, 10(1), 71-87.

Walsh, E., Buchanan, A., \& Fahy, T. (2002). Violence and schizophrenia: Examining the evidence. British Journal of Psychiatry, 180, 490-498.

Walsh, K. (1996). Philosophical hermeneutics and the projects of Hans Georg Gadamer: Implications for nursing research. Nursing Inquiry, 3, 231-237.

Watts, J. \& Priebe, S. (2002). A phenomenological Account of users' experiences of assertive community treatment. Bioethics, 16(5), 439-454. 
Whaley, A. L. (2004a). Paranoia in African American men receiving inpatient psychiatric treatment. The Journal of the American Academy of Psychiatry and the Law, 32, 282-290.

Whaley, A. L. (2004b). A two-stage method for the study of cultural bias in the diagnosis of schizophrenia in African Americans. Journal of Black Psychology, 30(2), 167186.

Williams, D. R., \& Williams-Morris, R. (2000). Racism and mental health: the African American experience. Ethnicity \& Health, 5(3), 243-268.

Williams, R. A. (Ed.). (2007). Eliminating healthcare disparities in American. Totowa, New Jersey: Humana Press. 
Appendix A

Initial IRB Approval Letter (3/16/11) 
Appendix B

IRB Amendment Approval Letter (7/28/11) 